\title{
Intermolecular Dissociation Energies of Hydrogen-Bonded 1-Naphthol Complexes
}

\author{
Richard Knochenmuss, Rajeev K. Sinha, ${ }^{*}$ Anja Poblotzki, ${ }^{\dagger}$ Takuya Den, and Samuel Leutwyler ${ }^{\ddagger}$ \\ Department of Chemistry and Biochemistry, \\ University of Bern, Freiestrasse 3, CH-3012 Bern, Switzerland
}

(Dated: November 5, 2018)

\begin{abstract}
We have measured the intermolecular dissociation energies $D_{0}$ of supersonically cooled 1-naphthol $(1 \mathrm{NpOH})$ complexes with the solvents $\mathrm{S}=$ furan, thiophene, 2,5-dimethylfuran and tetrahydrofuran. The naphthol $\mathrm{OH}$ forms non-classical H-bonds to the aromatic $\pi$-electrons of furan, thiophene and 2,5dimethylfuran, and a classical H-bond to the tetrahydrofuran $\mathrm{O}$ atom. Using the stimulated-emission pumping resonant two-photon ionization (SEP-R2PI) method, the ground-state $D_{0}\left(S_{0}\right)$ values were bracketed as $21.8 \pm 0.3 \mathrm{~kJ} / \mathrm{mol}$ for furan, $26.6 \pm 0.6 \mathrm{~kJ} / \mathrm{mol}$ for thiophene, $36.5 \pm 2.3 \mathrm{~kJ} / \mathrm{mol}$ for 2,5-dimethylfuran and $37.6 \pm 1.3 \mathrm{~kJ} / \mathrm{mol}$ for tetrahydrofuran. The dispersion-corrected density functional theory (DFT-D) methods B97-D3, B3LYP-D3 (using the def2-TZVPP basis set) and $\omega$ B97X-D [using the 6-311++G(d,p) basis set] predict that the H-bonded (Edge) isomers are more stable than the Face isomers bound by dispersion; experimentally, we only observe Edge isomers. We compare the calculated and experimental $D_{0}$ values and extend the comparison to the previously measured $1 \mathrm{NpOH}$ complexes with cyclopropane, benzene, water, alcohols and cyclic ethers. The dissociation energies of the nonclassically H-bonded complexes increase roughly linearly with the average polarizability of the solvent, $\bar{\alpha}(\mathrm{S})$. In contrast, the $D_{0}$ values of the classically H-bonded complexes are larger, increase more rapidly at low $\bar{\alpha}(\mathrm{S})$ but saturate for large $\bar{\alpha}(\mathrm{S})$. The calculated $D_{0}\left(S_{0}\right)$ values for the cyclopropane, benzene, furan and tetrahydrofuran complexes agree with experiment to within $1 \mathrm{~kJ} / \mathrm{mol}$, those of thiophene and 2,5-dimethylfuran are $\sim 3 \mathrm{~kJ} / \mathrm{mol}$ smaller than experiment. The B3LYP-D3 calculated $D_{0}$ values exhibit the lowest mean absolute deviation (MAD) relative to experiment $(\mathrm{MAD}=1.7 \mathrm{~kJ} / \mathrm{mol})$, the $\mathrm{B} 97-\mathrm{D} 3$ and $\omega \mathrm{B} 97 \mathrm{X}-\mathrm{D}$ MADs are 2.2 and $2.6 \mathrm{~kJ} / \mathrm{mol}$, respectively.
\end{abstract}

Keywords: non-classical hydrogen bond, classical hydrogen bond, dispersion interactions, intermolecular binding energies 


\section{INTRODUCTION}

Classical hydrogen bonds are considered to have important electrostatic and charge-transfer character, supplemented by smaller contributions from dispersion interactions. ${ }^{1-5}$ The opposite holds for the weaker "nonclassical" $\mathrm{OH} \cdots \pi, \mathrm{NH} \cdots \pi, \mathrm{CH} \cdots \mathrm{O}$ or $\mathrm{CH} \cdots \pi$ hydrogen bonds. ${ }^{3-6}$ The latter intermolecular interactions play important roles for the structure, stability and the dynamic properties of peptides, proteins, open-chain nucleic acids and tRNAs. ${ }^{1-4,6}$

Due to their comparative weakness, the accurate theoretical treatment of nonclassical hydrogen bonds is challenging. The introduction of dispersion-corrected density functionals tailored to include long-range correlation effects (DFT-D) has been a major advance. ${ }^{7-12}$ However, the benchmark sets for intermolecular interactions on which the DFT-D dispersion corrections have been tested are themselves mostly based on calculations. Hobza and co-workers have created benchmark sets for noncovalent interactions of biochemical relevance, denoted S22, ${ }^{13} \mathrm{~S} 66,{ }^{14} \mathrm{~S} 66 \mathrm{a} 8{ }^{15}$ and S66x8. ${ }^{16}$ The calculated S22 interaction energies have later been improved by the groups of Szalewicz ${ }^{17}$ and of Sherrill. ${ }^{18}$ The recent NCIBLIND10 benchmark set for intermolecular interactions, which is based on 80 benchmark energies for 10 different dimers computed at the $\operatorname{CCSD}(\mathrm{T})$ level and using complete basis set extrapolations, is also entirely computational. ${ }^{19}$ The non-covalent interaction energy part of the large GMTKN30 database ${ }^{11,12}$ is also mainly based on calculations. Only six noble gas dimer dissociation energies ${ }^{20,21}$ out of 95 noncovalent interaction energies in GMTKN30 are experimental values. The problems of theory $\leftrightarrow$ theory benchmarking and advantages of experiment $\leftrightarrow$ theory benchmarking were recently highlighted by Mata and Suhm. ${ }^{22}$

Thus, the ground-state intermolecular dissociation energies $D_{0}\left(S_{0}\right)$ of nonclassically H-bonded gas-phase complexes are important benchmark observables for testing theory. However, the number of experimental dissociation energies that can serve as benchmarks is still quite limited. $^{23-28}$ Neusser and co-workers have determined $D_{0}\left(S_{0}\right)$ values for the indole-benzene and 3-methylindole benzene complexes, for which they postulated an $\mathrm{NH} \cdots \pi \mathrm{H}$-bond between the indole and benzene moieties. ${ }^{24,25,29}$ Knee et al. have inferred an excited-state dissociation energy $D_{0}\left(S_{1}\right)=16.7 \pm 1.7 \mathrm{~kJ} / \mathrm{mol}$ for phenol-benzene , using picosecond-resolved photofragment spectroscopy. ${ }^{30}$ From this one obtains a ground-state $D_{0}\left(S_{0}\right)$ of $15.0 \pm 1.7 \mathrm{~kJ} / \mathrm{mol}$, using the

spectral shift of the electronic origin bands between phenol and phenol-benzene. ${ }^{30,31}$ Zwier and co-workers determined the $D_{0}$ of the jet-cooled $\mathrm{HOH}$ - benzene complex to lie between 6.8 and 
$11.6 \mathrm{~kJ} / \mathrm{mol} .^{32}$ Courty et al. have subsequently narrowed this value to $D_{0}=10.2 \pm 0.4 \mathrm{~kJ} / \mathrm{mol}^{33}$ Accurate dissociation energies of classically $\mathrm{H}$-bonded dimers and small clusters containing $\mathrm{H}_{2} \mathrm{O}$, $\mathrm{D}_{2} \mathrm{O}$ and $\mathrm{HCl}$ have been measured by the Reisler group. ${ }^{34-38}$

The aim of this work is to provide new experimental $D_{0}\left(S_{0}\right)$ values of nonclassically and classically H-bonded gas-phase complexes as benchmarks for dispersion-corrected DFT methods and high-level correlated quantum chemical methods. ${ }^{22,28,39-42}$ We have previously measured dissociation energies of complexes involving the 1-naphthol (1NpOH) UV chromophore, using the stimulated emission pumping-resonant two-photon ionization (SEP-R2PI) method. ${ }^{43-45}$ 1-Naphthol is small enough to be treated by high-level theoretical methods, but large enough to offer two intermolecular binding sites: Adsorption over the naphthalene ring gives rise to Face structures that are dominantly bound by dispersion interactions, ${ }^{43,46-52}$ whereas the $\mathrm{OH}$ group acts as an $\mathrm{H}$-bond donor, giving rise to Edge structures. ${ }^{23,27,49,50,53}$ Recently, we have determined $D_{0}\left(S_{0}\right)$ values of $1 \mathrm{NpOH}$ Face complexes with solvent atoms and molecules ranging from noble gases to $n$-alkanes, 49-52,54 where the adatom or admolecule interacts with the naphthalene rings via London dispersion interactions. However, the cyclopropane complex also forms an Edge isomer that involves a non-classical $\mathrm{H}$-bond from the $\mathrm{OH}$ group to a cyclopropane $\mathrm{C}-\mathrm{C}$ bond. ${ }^{49,51} 1 \mathrm{NpOH}$ also forms a nonclassical $\mathrm{OH} \cdots \pi$ hydrogen bond to benzene, in which the $C_{6}$ axis of the benzene moiety lies roughly parallel to the 1-naphthol $\mathrm{OH}$ bond axis. ${ }^{55} D_{0}\left(S_{0}\right)$ values have also been measured "classical" $\mathrm{OH} \cdots \mathrm{O}$ and $\mathrm{OH} \cdots \mathrm{N}$ hydrogen-bonded complexes of $1 \mathrm{NpOH}$ with the acceptors molecules $\mathrm{H}_{2} \mathrm{O}, \mathrm{D}_{2} \mathrm{O}$, methanol, ethanol, oxirane, oxetane, ammonia and ammonia- $d_{3}$, which have localized lone-pair electrons on their heteroatoms. ${ }^{27,53}$

Below, we determine non-classical H-bond dissociation energies for the polar heteroaromatics furan and thiophene. We study the effect of aromaticity vs. non-aromaticity by comparing the furan and tetrahydrofuran (THF) complexes, where the latter forms a classical H-bond. We also measure the effect of adding methyl groups to furan by studying the 2,5-dimethylfuran (2,5-DMF) complex. Analogous methanol-furan and methanol-2,5-DMF complexes have been investigated by IR spectroscopy in slit supersonic jets, with a focus on the relative energies of the $\mathrm{OH} \cdots \mathrm{O}$ and $\mathrm{OH} \cdots \pi$ forms, also termed an "intermolecular energy balance". ${ }^{56-58}$ Here, we provide the absolute dissociation energy, albeit with 1-naphthol replacing methanol as an H-bond donor. Finally, we compare the experimental $D_{0}$ values to those calculated with the widely-used dispersion-corrected density functional theory (DFT) methods B3LYP-D3, B97-D3 and $\omega$ B97X-D. ${ }^{8-11,59}$ 


\section{METHODS}

\section{A. The SEP-R2PI Method}

We have previously described the SEP-R2PI method, ${ }^{28,49-51}$ which is schematically explained in the supplemental Figure S1 (SI). The supersonically cooled $1 \mathrm{NpOH} \cdot \mathrm{S}$ complexes are pumped by a $\sim 5$ ns pulsed tunable UV laser set to the electronic origin band of the $S_{0} \rightarrow S_{1}$ transition, exciting the complex to the $S_{1} ; v^{\prime}=0$ vibrationless level. A minor portion of the generated $S_{1}$ complexes is directly ionized by a second photon of the pump laser. In the following dump step, a second independently tunable UV laser transfers a large fraction of the $S_{1} ; v^{\prime}=0$ population down to a specific $S_{0}$ state intra- or intermolecular vibrational level with $v_{i}^{\prime \prime}>0$. The dump laser is scanned toward low wavenumber, corresponding to increasing $S_{0}$ state vibrational energy. Because of the large level density of the intra- and intermolecular vibrational modes even at low vibrational energy $E\left(v^{\prime \prime}\right)$, the microcanonically hot $1 \mathrm{NpOH} \cdot \mathrm{S}$ complexes undergo rapid intermolecular vibrational redistribution (IVR). The population transfer efficiency achieved in the SEP process [pump+dump+IVR] depends on the electronic oscillator strength $f_{e l}$ and the FranckCondon factors in absorption and (stimulated) emission and on the vibration-dependent IVR rates in the $S_{0}$ state. While other $S_{1}$ state processes such as internal conversion and intersystem crossing influence the overall SEP efficiency, they do not affect the SEP spectrum. After a $3 \mu$ s delay that allows IVR to go to completion, the microcanonically hot $1 \mathrm{NpOH} \cdot \mathrm{S}$ complexes are detected by R2PI with a third tunable UV pulsed laser, denoted the probe laser. This delay is long enough to permit the hot $S_{0}$ state complexes to couple to the intermolecular dissociative coordinates. ${ }^{50,54}$

For the $D_{0}\left(S_{0}\right)$ measurement, we first determine the energies of the optically active $S_{0}\left(v_{i}^{\prime \prime}>0\right)$ vibrational levels by recording the decrease of the R2PI ion signal of the 1-naphthol-S complex in the pump+dump step while scanning the dump laser. Alternatively, the dispersed fluorescence emission spectrum is excited at the $0_{0}^{0}$ band, see Figure $S 1$. The dump and fluorescence spectra are both $S_{1} ; v^{\prime}=0 \rightarrow S_{0}$ vibronic spectra, which have identical $f_{e l}$ and Franck-Condon factors. However, the band intensities may differ because the dump spectra depend on the $S_{0}$ state IVR, which depletes the lower state, while the fluorescence spectrum does not. Below we will show the spectrum that exhibits the better signal/noise ratio. In the second measurement, the probe laser is

fixed at a hot band (or sequence band) of $1 \mathrm{NpOH} \cdot \mathrm{S}$ complex that originates from a $v^{\prime \prime}>0$ level, so the dump transitions are detected as positive-going hot-band SEP-R2PI signal. Hot-band SEP 
signals are only observed if the microcanonically hot $S_{0}$ state $1 \mathrm{NpOH} \cdot \mathrm{S}$ complex remains bound during the entire $3 \mu$ s pump-probe delay time, see the supplemental Figure S1 (SI). If the dump laser excites vibrations of $1 \mathrm{NpOH} \cdot \mathrm{S}$ that lie above $D_{0}\left(S_{0}\right)$, IVR is followed by $1 \mathrm{NpOH} \leftrightarrow \mathrm{S}$ vibrational predissociation, the complex falls apart during the $3 \mu$ s delay and the hot-band SEP-R2PI spectrum breaks off. The ground-state dissociation energy $D_{0}\left(S_{0}\right)$ of the complex is bracketed between the highest-wavenumber dump transition observed in the hot-band SEP spectrum and the lowest-wavenumber band that is not observed in the hot-band SEP spectrum, but appears in the dump or dispersed fluorescence spectra.

\section{B. Experimental}

The supersonically cooled $1 \mathrm{NpOH} \cdot \mathrm{S}$ complexes were produced by co-expanding $1 \mathrm{NpOH}$ (Fluka, 99\%) and $0.1-0.2 \%$ of furan, thiophene, 2,5-DMF or THF (Sigma-Aldrich, purity $>$ $99 \%)$. The admolecules were premixed in Ne carrier gas, the total backing pressures were $1.4-1.6$ bar. The $1 \mathrm{NpOH}$ was heated to $347 \mathrm{~K}$ ( 0.3 mbar vapor pressure). Two frequency-doubled tunable dye lasers (Lambda Physik FL2002 and FL3002, fundamental range 620 - $660 \mathrm{~nm}$ ) were employed as pump $(0.5-1 \mathrm{~mJ} /$ pulse $)$ and dump $(1-2 \mathrm{~mJ} /$ pulse $)$ lasers, both pumped by the same Nd:YAG laser (Innolas Spitlight 600). The probe dye laser (Lambda Physik LPD 3000, 0.3 $\mathrm{mJ} /$ pulse) was pumped by a Continuum Surelite II frequency-doubled Nd:YAG. The dye-laser wavelength and bandwidths before frequency doubling were monitored using a HighFinesse WS6 wavemeter; the bandwidths were $0.3-0.4 \mathrm{~cm}^{-1}$. The probe laser was time-delayed by $3 \mu$ s and crossed the molecular beam $3 \mathrm{~mm}$ downstream of the pump and dump lasers, to compensate for the $\sim 950 \mathrm{~m} / \mathrm{s}$ mean speed of the molecular beam. Other experimental details are as reported previously. $^{49-52}$

Mass-selective one-color resonant two-photon ionization (R2PI) spectra were recorded by exciting and ionizing in the ion-source of a $120 \mathrm{~cm}$ long linear time-of-flight mass spectrometer. UV/UV hole-burning spectra were also measured for all complexes. $S_{1} \rightarrow S_{0}$ dispersed fluo-

rescence spectra were measured by exciting the $0_{0}^{0}$ band of the respective complex isomer. The fluorescence emission was collected with fused silica optics and detected in the second order of a SOPRA UHRS F1500 1.5 m monochromator using a Hamamatsu R928 photomultiplier. The slit width was $200 \mu \mathrm{m}$, equivalent to a bandpass of $28 \mathrm{pm}\left(\sim 3 \mathrm{~cm}^{-1}\right)$, the spectra were scanned in 2.5 pm steps. 


\section{Theoretical Methods}

The minimum-energy structures and harmonic vibrational frequencies of the $1 \mathrm{NpOH} \cdot \mathrm{S}$ complexes were calculated with three different dispersion-corrected density functional theory (DFT-D) methods. The B97-D $3^{7}$ and B3LYP-D $3^{60}$ methods were employed with the def2-TZVPP basis set using Gaussian16. ${ }^{61}$ For comparison, we employed the Chai-Gordon long-range and dispersioncorrected $\omega$ B97X-D functional, ${ }^{9}$ as implemented in Gaussian $16,{ }^{61}$ using the $6-31++\mathrm{G}(\mathrm{d}, \mathrm{p})$ basis set. The latter two methods have given good results in studies of large $\pi$-stacked complexes. ${ }^{62,63}$ All structure optimizations were unconstrained. The binding energies $D_{e}$ were calculated by subtracting the total energies of trans-1-naphthol and of the solvent molecule $\mathrm{S}$ - both optimized at their respective isolated-molecule geometries - from the total energy of the 1-naphthol.S complex at its optimized minimum-energy geometry. The Boys-Bernardi counterpoise $(\mathrm{CP})$ correction for basis set superposition error was used for the $\omega \mathrm{B} 97 \mathrm{X}-\mathrm{D}$ calculation. With the def2-TZVPP basis set the BSSE effects start to be negligible ${ }^{7}$ and we did not perform CP corrections. The larger def2-QZVPP basis set led to prohibitively large computational costs and could not be employed.

The harmonic frequencies and vibrational zero point energies (VZPEs) of the monomers and complexes were calculated with all three DFT methods at the same level as the optimized structures. The dissociation energies $D_{0}$ were calculated as $D_{0}=D_{e}-\Delta \mathrm{VZPE}$, using the change in zero-point energies $\triangle \mathrm{VZPE}$, given by $\triangle \mathrm{VZPE}=\mathrm{VZPE}($ complex $)-\operatorname{VZPE}(1 \mathrm{NpOH})-\mathrm{VZPE}(n-$ alkane). For all complexes investigated here, the DFT-D calculations predict both Face and Edge structures. The latter are predicted to be more strongly bound than the Face isomers, which is confirmed by the experiment.

\section{RESULTS}

\section{A. Resonant two-photon ionization spectra}

Figure 1 shows the one-color R2PI spectra of bare 1-naphthol and of the 1-naphthol.S complexes with $\mathrm{S}=$ thiophene, furan, 2,5-DMF and THF in the region of their $S_{0} \rightarrow S_{1} 0_{0}^{0}$ bands. The spectra in Figure 1(b-e) exhibit weak vibronic bands that correspond to the excitation of $S_{1}$ state intermolecular vibrational fundamentals and overtones or combinations thereof. These give information on the intermolecular frequencies. In Figure 1 we also indicate band assignments of different isomers (A, B, C) of the furan and THF complexes, which were established by UV/UV 
hole-burning spectroscopy, see below.

The $0_{0}^{0}$ bands of the complexes are shifted relative to the 1-naphthol $0_{0}^{0}$ (at $31455.7 \mathrm{~cm}^{-1}$ ) by the spectral shift $\delta \tilde{\nu}$. A thermochemical cycle ${ }^{47,64,65}$ shows that $\delta \tilde{\nu}$ corresponds to the difference of the ground- and excited-state dissociation energies, $\delta \tilde{\nu}=D_{0}\left(S_{0}\right)-D_{0}\left(S_{1}\right)$, see also Figure S1. The spectral shift is empirically observed to be a good predictor of the binding topology of $1 \mathrm{NpOH} \cdot \mathrm{S}$ complexes. ${ }^{4-52,54}$ The Face complexes exhibit small spectral shifts between $\delta \tilde{\nu}=+5$ and $-10 \mathrm{~cm}^{-1}$, e.g., the Face isomer of $1 \mathrm{NpOH} \cdot$ cyclopropane exhibits a small blue shift of $\delta \tilde{\nu}=+2 \mathrm{~cm}^{-1}$. The spectral shifts of the Edge complexes are large and to the red, thus $\delta \tilde{\nu}=-72 \mathrm{~cm}^{-1}$ for the Edge isomer of $1 \mathrm{NpOH} \cdot$ cyclopropane. ${ }^{49}$

1-Naphthol-thiophene: The R2PI spectrum in Figure 1(b) shows an intense $S_{0} \rightarrow S_{1}$ electronic origin at $31387 \mathrm{~cm}^{-1}$, which is red-shifted by $\delta \tilde{\nu}=-69 \mathrm{~cm}^{-1}$, indicating that this is an Edge complex. UV/UV holeburning measurements revealed that the entire spectrum arises from a single isomer. We assign the bands at $0_{0}^{0}+9,+50$ and $+57 \mathrm{~cm}^{-1}$ as fundamentals of the intermolecular vibrations $\nu_{X}^{\prime}$ (calculated at $\left.14 \mathrm{~cm}^{-1}\right), \nu_{\text {rot, } 1}^{\prime}$ (calculated at $55 \mathrm{~cm}^{-1}$ ) and a weak combination band $\nu_{X}^{\prime}+\nu_{r o t, 1}^{\prime}$. The calculated intermolecular B97-D3 frequencies are given in Table I.

1-Naphthol-furan: UV/UV spectral holeburning of $1 \mathrm{NpOH} \cdot$ furan reveal that two isomers contribute to the R2PI spectrum in Figure 1(c). The isomer spectra are shown in the supplemental Figure S2. They overlap strongly, and isomer separation by UV/UV-holeburning was only partially possible. The more strongly populated isomer, which we denote A, exhibits a strong origin band that is redshifted by $\delta \tilde{\nu}=-81 \mathrm{~cm}^{-1}$. Isomer B contributes about $30 \%$ to the spectrum, its spectral shift is slightly smaller than that of isomer A, making the separation of the contributions difficult. Its intermolecular vibrational bands, four of which are marked by (B) in Figure 1(c), also overlap with those of isomer A. For this reason, the $0_{0}^{0}$ band of isomer B could not be definitely located and the dissociation energies of the furan complex could not be measured separately for the two isomers. Since the spectral shifts are large, we assign both isomers as hydrogen-bonded Edge structures.

1-Naphthol-2,5-dimethylfuran: The one-color R2PI spectrum of the 1NpOH·2,5-DMF complex in Figure $1(\mathrm{~d})$ is spectrally shifted by $\delta \tilde{\nu}=-93 \mathrm{~cm}^{-1}$, slightly farther than the furan complex. We also assign it as an Edge complex. UV/UV spectral holeburning show that the entire spectrum arises from a single isomer. The $0_{0}^{0}$ band is considerably broader than those of the thiophene and 
furan complexes, we interpret this as arising from a stronger coupling of the $S_{0} \rightarrow S_{1}$ electronic excitation to the low-frequency intermolecular vibrations. This implies that the intermolecular coordinates of the DMF complex undergo a larger change upon electronic excitation than the other complexes. We assign the bands observed at $8,11,31$ and $77 \mathrm{~cm}^{-1}$ above the $0_{0}^{0}$ band to the fundamentals of the intermolecular vibrations $\nu_{X}^{\prime}$ (calculated to be $4.5 \mathrm{~cm}^{-1}$ ), $\nu_{Y}^{\prime}$ (calculated $20 \mathrm{~cm}^{-1}$ ), $\nu_{Z}^{\prime}$ (calculated $47 \mathrm{~cm}^{-1}$ ) and $\nu_{r o t, 3}^{\prime}$ (calculated $77 \mathrm{~cm}^{-1}$ ). The calculated intermolecular B97-D3 frequencies are also included in Table I.

1-Naphthol-tetrahydrofuran: The R2PI spectrum in Figure 1(e) shows an intense and wellstructured electronic origin at $31262 \mathrm{~cm}^{-1}$. The spectral shift is $\delta \tilde{\nu}=-194 \mathrm{~cm}^{-1}$, about twice that of the 2,5-DMF complex and more than twice that of the furan complex. The spectral shift is close to that of the $1 \mathrm{NpOH} \cdot$ oxetane complex $\left(\delta \tilde{\nu}=-184 \mathrm{~cm}^{-1}\right) .{ }^{27}$ Oxetane and THF are homologous four- and five-ring cyclic ethers, so the similarity of the spectral shifts also argues for an Edge structure. UV/UV holeburning spectra revealed that at least three isomers contribute to the $0_{0}^{0}$ band in Figure 1(e). We denote these A, B and C, their respective spectral shifts are $\delta \tilde{\nu}=-194,-183$ and $-172 \mathrm{~cm}^{-1}$. As for the furan complex, it was difficult to separate the R2PI spectra by UV/UV holeburning, due to the overlap of the three isomers.

The free THF molecule undergoes pseudorotational isomerization across low potential energy barriers, leading to two equivalent "envelope", two equivalent "twisted", and four equivalent asymmetric stationary points on the THF potential-energy surface. ${ }^{66}$ These pseudorotational conformations may freeze into different minima upon jet-cooling and complex formation. This would explain the formation of isomers with only slightly different spectral shifts. Increasing the stagnation pressure decreases the vibrational temperature of the complex and changes the shape of the $0_{0}^{0}$ band: The contributions from isomers $\mathrm{A}$ and $\mathrm{C}$ decrease strongly relative to that of isomer $\mathrm{B}$, but they still contribute to the width of the band. At lower temperature the lowest-energy band shifts slightly to the blue, to $31273 \mathrm{~cm}^{-1}$. The corresponding R2PI spectra are shown in supplemental Figure S3 (SI). As for the furan complex, the dissociation energies $D_{0}$ of the THF complex isomers could not be measured separately.

\section{B. Experimental Dissociation Energies}

1-Naphthol-thiophene: Figure 2(a) shows the hot-band probed SEP-R2PI spectrum, which was measured with the probe laser set to a broad hot-band signal at $0_{0}^{0}-47 \mathrm{~cm}^{-1}$, as shown in the sup- 
plemental Figure S4 (SI). The R2PI spectrum of pump/dumped 1NpOH·thiophene is also shown in Figure S4. The dump spectrum of $1 \mathrm{NpOH}$-thiophene in Figure 2(b) is similar to the hot-band SEP spectrum in Figure 2(a) up to the band at $2173 \mathrm{~cm}^{-1}$. The following vibronic band at $2268 \mathrm{~cm}^{-1}$ and subsequent bands to higher energy in Figure 2(b) are not observed in (a). Thus, the $2173 \mathrm{~cm}^{-1}$ and the $2268 \mathrm{~cm}^{-1}$ bands in Figure 2 bracket the ground-state $D_{0}\left(S_{0}\right)$ of $1 \mathrm{NpOH} \cdot$ thiophene complex as $2221 \pm 48 \mathrm{~cm}^{-1}$. The excited-state dissociation energy $D_{0}\left(S_{1}\right)$ is obtained by subtracting the experimental spectral shift of the origin band $\left(\delta \tilde{\nu}=-69 \mathrm{~cm}^{-1}\right)$ from the $D_{0}$ of the ground state, giving $D_{0}\left(S_{1}\right)=2290 \pm 48 \mathrm{~cm}^{-1}$, see also Table II.

Note that the \pm limits mentioned below are the limits of the bracketing interval and should not be taken as the statistical standard deviation of the experimental mean value of the measurement. The true dissociation energy may lie anywhere within the bracketed interval with equal probability.

1-Naphthol-furan: Figure 3(a) shows the hot-band probed SEP-R2PI spectrum of 1NpOH·furan with the probe laser set to $0_{0}^{0}-83 \mathrm{~cm}^{-1}$. The pump laser was set to the $0_{0}^{0}$ band of isomer $\mathrm{A}$ at $31375 \mathrm{~cm}^{-1}$, see Figure 1(c). As discussed in section III A, this band overlaps with the $0_{0}^{0}$ band of isomer B, so the SEP-R2PI measurement does not discriminate between the two isomers.

The dump spectrum in Figure 3(b) mirrors the hot-band SEP spectrum in Figure 3(a) up to $1800 \mathrm{~cm}^{-1}$. The following bands at $1848 \mathrm{~cm}^{-1}$ and above in the dump spectrum in Figure 3(b) are not observed in spectrum (a). Note that the $1800 \mathrm{~cm}^{-1}$ band corresponds to the lower $D_{0}$ limit of the more stable ground-state isomer (the signal breakoff from the minor isomer B might go unnoticed if its $D_{0}$ were smaller). Thus, the 1800 and $1848 \mathrm{~cm}^{-1}$ bands in Figure 3(a,b) bracket the $D_{0}\left(S_{0}\right)$ of the more stable isomer of $1 \mathrm{NpOH}$-furan as $1824 \pm 24 \mathrm{~cm}^{-1}$. The excited-state dissociation energy $D_{0}\left(S_{1}\right)=1905 \pm 25 \mathrm{~cm}^{-1}$ is obtained from the spectral shift of the $0_{0}^{0}$ band $\left(\delta \tilde{\nu}=-81 \mathrm{~cm}^{-1}\right)$, see also Table II.

1-Naphthol-2,5-dimethylfuran: Figure 4(a) shows the hot-band probed SEP-R2PI spectra of $1 \mathrm{NpOH} \cdot 2,5-\mathrm{DMF}$. The pump laser was set to the $0_{0}^{0}$ band and the probe laser to $0_{0}^{0}-34 \mathrm{~cm}^{-1}$. The fluorescence spectrum of this complex shown in Figure 4(b) exhibits better signal/noise ratio than the dump spectrum. Mirror symmetry between the two spectra is observed up to and including a weak band at $3024 \mathrm{~cm}^{-1}$. The next significant band in the fluorescence spectrum is observed at $3243 \mathrm{~cm}^{-1}$, but this and the following vibronic bands in the fluorescence spectrum are not observed in spectrum Figure 4(a). Thus, at first sight, the 3024 and $3243 \mathrm{~cm}^{-1}$ bands in Figure 4 
bracket the $D_{0}\left(S_{0}\right)$ of $1 \mathrm{NpOH} \cdot 2,5-\mathrm{DMF}$ as $3134 \pm 110 \mathrm{~cm}^{-1}$.

However, this experimental $D_{0}$ is $15-25 \%$ larger than the three DFT-D calculated values discussed below. In contrast, the calculated $D_{0}$ values for $1 \mathrm{NpOH}$-furan and $1 \mathrm{NpOH} \cdot \mathrm{THF}$ lie close to or within the experimental $D_{0}$ brackets. The good agreement between experiment and theory for the furan and THF complexes but not for the 2,5-DMF complex calls for closer examination. In previous work on the SEP-R2PI detected dissociation energies of $1 \mathrm{NpOH} \cdot \mathrm{methane}$ and $1 \mathrm{NpOH} \cdot$ ethane, we noted weak bands in the hot-band detected SEP spectra that we interpreted as long-lived metastable vibrational levels lying above the putative dissociation limit. ${ }^{54}$ The metastability was tentatively explained in terms of the large contribution of the low-wavenumber methane or ethane surface-rotational and internal-rotation modes to the vibrational level density $\rho_{v i b}$, combined with the weak coupling of these IVR-populated states to the intermolecular dissociation coordinate. ${ }^{54}$ For the methane and ethane complexes the $D_{0}$ brackets were revised downward accordingly. ${ }^{54}$

Given the two methyl groups of 2,5-DMF, the weak vibronic band at $3024 \mathrm{~cm}^{-1}$ might correspond to a level that is metastable with respect to vibrational predissociation. The two lowest calculated vibrations of 2,5-DMF are indeed methyl torsions, but with calculated harmonic wavenumbers of 132 and $145 \mathrm{~cm}^{-1}$, these are $2-30$ times larger that the harmonic frequencies of the six intermolecular modes given in Table I. Thus, while the two methyl torsions of 2,5-DMF do contribute to the $\rho_{v i b}$ of the complex, they do not dominate it to the extent that occurs in the methane and ethane complexes. The intermolecular and methyl-rotor vibrations are highly anharmonic, so it is not currently possible to accurately calculate the anharmonic $\rho_{v i b}$ required to discuss these effects quantitatively. Also, there might be nuclear-spin symmetry restrictions on the methyl-rotor states that affect both the IVR into and the vibrational predissociation of these levels. We conclude that the $3024 \mathrm{~cm}^{-1}$ level is a borderline case: If it is indeed metastable, it is an upper limit to $D_{0}$, the lower limit then being determined by the band at $2861 \mathrm{~cm}^{-1}$. We therefore give conservatively estimated brackets 2861 and $3243 \mathrm{~cm}^{-1}$, as indicated in Figure 4, leading to a $D_{0}\left(S_{0}\right)=3052 \pm 191 \mathrm{~cm}^{-1}$. With the spectral shift $\delta \tilde{\nu}=-93 \mathrm{~cm}^{-1}$ of the $0_{0}^{0}$ band we obtain the excited-state dissociation energy $D_{0}\left(S_{1}\right)=3145 \pm 191 \mathrm{~cm}^{-1}$, see also Table II.

1-Naphthol-tetrahydrofuran: Figure 5(a) shows the hot-band probed SEP-R2PI spectrum of the $1 \mathrm{NpOH} \cdot \mathrm{THF}$ complex, with the pump laser set to the $0_{0}^{0}$ band of isomer $\mathrm{B}$, The probe laser was set to $0_{0}^{0}-63 \mathrm{~cm}^{-1}$, see Figure S5 (SI). Note that isomers $\mathrm{A}$ and $\mathrm{C}$ are also optically excited 
at this wavenumber, albeit less strongly. Similar to the 1-naphthol-furan measurement, this $D_{0}$ determination is not isomer-selective. The fluorescence spectrum upon excitation at $31274 \mathrm{~cm}^{-1}$ is shown in Figure 5(b). In trace (a) the spectrum breaks off at the weak vibronic band at $3038 \mathrm{~cm}^{-1}$. The lowest-energy vibronic band that is not observed in Figure 5(a) lies at $3253 \mathrm{~cm}^{-1}$. Thus, the two bands at 3038 and $3253 \mathrm{~cm}^{-1}$ in Figure 5 bracket the $D_{0}\left(S_{0}\right)$ of $1 \mathrm{NpOH} \cdot \mathrm{THF}$ complex as $3146 \pm 108 \mathrm{~cm}^{-1}$, see Table II. With the spectral shift $\delta \tilde{\nu}=-182 \mathrm{~cm}^{-1}$ we obtain the excited-state dissociation energy $D_{0}\left(S_{1}\right)=3328 \pm 108 \mathrm{~cm}^{-1}$, see also Table II.

\section{Calculated Structures}

The B97-D3, B3LYP-D3 and $\omega$ B97X-D calculated lowest energy structures are always Edge isomers. We located and optimized two Edge isomers of the thiophene and 2,5-DMF complexes, three isomers of the furan complex and four of the THF complex. We also optimized a Face isomer for the thiophene, furan and 2,5-DMF complexes. However, these are local minima that lie $7-12 \mathrm{~kJ} / \mathrm{mol}$ higher than the Edge minima.

The DFT-D calculations predict a large range of relative angular orientations of the $1 \mathrm{NpOH}$ and $\mathrm{S}$ moieties in the different isomers. More than half of the isomers are predicted to be $C_{1}$ symmetric and thus exist as a pair of enantiomers. Furthermore, different DFT methods predict different isomer geometries, so the structures shown in the Figures should be considered as examples. The calculated Cartesian coordinates of all the complexes using all three methods are given in Tables S1-S34 (supplemental information).

The Edge isomers exhibit four different intermolecular contact types, where each isomer exhibits two of the four contact types:

(1) Classical $\mathrm{OH} \cdots \mathrm{X}(\mathrm{X}=\mathrm{O}, \mathrm{S})$ hydrogen bonds from the naphthol $\mathrm{OH}$ group to a lone-pair of the $\mathrm{X}$ atom. These $(\mathrm{O}) \mathrm{H} \cdots \mathrm{X}$ distances are short, being $R \sim 1.75-1.80 \AA$.

(2) Nonclassical $\mathrm{OH} \cdots \pi$ interactions, which involve a close contact between the $\mathrm{OH}$ group and an aromatic $\mathrm{C}$ atom, an aromatic $\mathrm{C}=\mathrm{C}$ bond or an aromatic heteroatom $\mathrm{X}$. The $(\mathrm{O}) \mathrm{H} \cdots \mathrm{X}$ distances are typically $R \sim 1.90-2.05 \AA$.

(3) Non-classical $\mathrm{CH} \cdots \mathrm{X}(\mathrm{X}=\mathrm{O}, \mathrm{S})$ contacts, with $\mathrm{H} \cdots \mathrm{X}$ distances of $R \sim 2.20-2.40 \AA$.

(4) (C) H $\cdots \mathrm{C}$ contacts with long distances $R \sim 2.85 \AA$, corresponding to the sum of van der Waals $(\mathrm{vdW})$ radii or longer. 
Figure 6 shows the $\omega \mathrm{B} 97 \mathrm{X}-\mathrm{D}$ calculated isomers 1 and 2 of the $1 \mathrm{NpOH}$-thiophene complex. Isomer 1 exhibits an $\mathrm{OH} \cdots \mathrm{S}$ hydrogen bond and a $\mathrm{CH} \cdots \mathrm{C}$ vdW contact. Isomer 2 combines a nonclassical $\mathrm{OH} \cdots \pi$ hydrogen bond and $\mathrm{CH} \cdots \pi$ vdW contact. Figure 7 shows the B97-D3 calculated isomers 1 and 2 of the $1 \mathrm{NpOH} \cdot$ furan complex. Isomer 1 is similar to Isomer 1 of the thiophene complex in combining an $\mathrm{OH} \cdots \mathrm{O}$ with a $\mathrm{CH} \cdots \pi$ vdW contact. Isomer 2 combines $\mathrm{OH} \cdots \pi$ and $\mathrm{CH} \cdots \mathrm{O}$ hydrogen bonds.

Figure 8 shows the Edge isomer 1 of the $1 \mathrm{NpOH} \cdot 2,5-\mathrm{DMF}$ complex, which is $C_{s}$ symmetric. Its $\mathrm{OH} \cdots \mathrm{O}$ (furan) hydrogen-bond distance is $1.92 \AA$. The Edge isomer 2 is predicted to be $1-4$ $\mathrm{kJ} / \mathrm{mol}$ less stable than isomer 1 . The spacefilling model in Figure 8(b) shows the proximity of one methyl group to the naphthalene plane. The ball-and-stick representation in Figure 8(c) shows the $\mathrm{OH} \cdots \pi$ hydrogen bond, which is predicted to be $0.38 \AA$ longer than the $\mathrm{OH} \cdots \mathrm{O} \mathrm{H}$-bond distance of isomer 1 .

Figure 9 shows the B97-D3 calculated structure of isomer 3 of the $1 \mathrm{NpOH} \cdot \mathrm{THF}$ complex. The calculated $D_{0}\left(S_{0}\right)$ values of the other isomers are $0.15-1.5 \mathrm{~kJ} / \mathrm{mol}$ smaller. For this complex, all the calculated isomers exhibit short and well-aligned $\mathrm{OH} \cdots \mathrm{O}$ hydrogen bonds with the THF unit twisted away from the plane of the $1 \mathrm{NpOH}$ moiety. The THF subunit of isomer 2 exists in two pseudorotational forms (see section III. A).

\section{DISCUSSION}

\section{A. Complex structures and spectral shifts}

Figure 1 shows that the complexes investigated in this work exhibit spectral shifts between $\delta \tilde{\nu}=-69 \mathrm{~cm}^{-1}$ for $1 \mathrm{NpOH} \cdot$ thiophene and $\delta \tilde{\nu}=-184 \mathrm{~cm}^{-1}$ for $1 \mathrm{NpOH} \cdot \mathrm{THF}$. As discussed above, large spectral red shifts are typical for Edge complexes involving classical or nonclassical hydrogen bonds. The UV/UV-holeburning spectra did not reveal any isomers with small spectral shifts. We therefore assign all the complexes as Edge complexes. If Face isomers are transiently formed during the supersonic jet expansion, they rapidly isomerize to the more stable Edge counterparts.

The spectral shift of the thiophene complex $\left(\delta \tilde{\nu}=-69 \mathrm{~cm}^{-1}\right)$ is close to those of $1 \mathrm{NpOH} \cdot \mathrm{benzene}$ $\left(\delta \tilde{\nu}=-66 \mathrm{~cm}^{-1}\right)^{23}$ and to that of the Edge isomer of $1 \mathrm{NpOH} \cdot$ cyclopropane $\left(\delta \tilde{\nu}=-72 \mathrm{~cm}^{-1}\right){ }^{49}$ The structure of $1 \mathrm{NpOH} \cdot$ benzene has been determined by rotational coherence spectroscopy 
(RCS), the benzene ring is orthogonal to the naphthalene ring and is arranged symmetrically with respect to the naphthalene plane. ${ }^{55}$ The geometry of the cyclopropane complex has not yet been experimentally determined, but DFT-D (PBE0-D3) and high-level correlated calculations predict an Edge structure with the $1 \mathrm{NpOH} \mathrm{OH}$ group pointing to the center of a cyclopropane $\mathrm{CC}$ bond. ${ }^{49}$

These similarities motivated a closer comparison. We performed calculations for the benzene and cyclopropane complexes using the same DFT-D methods as above. The B97-D3 calculated structure of $1 \mathrm{NpOH} \cdot$ benzene is shown in Figure 10. The $\sigma_{h}$ symmetry plane of benzene is orthogonal to that of the $1 \mathrm{NpOH}$ moiety and the $\mathrm{NpOH}$ forms $\mathrm{OH} \cdots \pi$ and $\mathrm{CH} \cdots \pi$ hydrogen bonds to the benzene ring. This geometry is in good agreement with the RCS structure proposed by Felker. ${ }^{55}$ The B97-D3 calculated structure of 1NpOH.cyclopropane is shown in Figure 11. It exhibits a single nonclassical $\mathrm{H}$-bond from the naphthol $\mathrm{OH}$ group to the center of a cyclopropane $\mathrm{C}-\mathrm{C}$ bond. The $\sigma_{h}$ plane of cyclopropane is perpendicular to that of the $1 \mathrm{NpOH}$ ring, but is oriented away from the $1 \mathrm{NpOH}$, roughly along the $\mathrm{OH}$ bond axis. The B97-D3, B3LYP-D3 and $\omega \mathrm{B} 97 \mathrm{X}-\mathrm{D}$ structures of the cyclopropane complex are very similar to those previously calculated with PBE0-D3 and high-level correlated methods. ${ }^{49}$

The structures of the high-symmetry complexes involving benzene and cyclopropane moieties lend themselves to interpretation in terms of nonclassical hydrogen bonds. However, the different isomers of the thiophene, furan, 2,5-DMF and THF Edge complexes cover a large range of geometries. Some of these isomers are difficult to describe in terms of H-bond interactions, either because the putative $\mathrm{H}$-bond to the admolecule originates from the weak $\mathrm{CH}$ donor and is long (i.e., a van der Waals contact distance or longer), or because the heteroatom $(\mathrm{O}, \mathrm{S})$ does not lie in the $1 \mathrm{NpOH}$ plane and the admolecule is tilted relative to the $1 \mathrm{NpOH}$ plane.

\section{B. Experimental dissociation energies}

In the first data column of Table III we collect the experimental dissociation energies of the 1-naphthol.S complexes and compare them to the calculated B97-D3, B3LYP-D3 and $\omega$ B97X-D $D_{0}$ values. The experimental and calculated $D_{0}$ values are also compared in Figure 12, where both are plotted vs. the isotropic (average) electronic polarizability $\bar{\alpha}$ of the S admolecule. Since each computational method predicts several isomers with different dissociation energies and we have no way of determining the structures in our experiment, we compare the experimental $D_{0}$ to that of the isomer with the largest dissociation energy predicted by the given DFT-D method. 
The $D_{0}=15.34 \mathrm{~kJ} / \mathrm{mol}$ of the cyclopropane complex is about half of those of the classically H-bonded complexes shown in the upper part of Figure 12 such as $1 \mathrm{NpOH}$-oxirane and $1 \mathrm{NpOH} \cdot$ oxetane. This much smaller $D_{0}$ is characteristic for nonclassical hydrogen bonding.

Replacing the nonaromatic cyclopropane by the aromatic furan increases the $D_{0}$ of the $1 \mathrm{NpOH}$ complex by $42 \%$. The average electronic polarizability of furan $\left(\bar{\alpha}=7.4 \AA^{3}\right)$ is $30 \%$ larger than that of cyclopropane $\left(\bar{\alpha}=5.66 \AA^{3}\right)$ so the increase in $D_{0}$ for the furan complex is larger than would be expected from the relative polarizabilities, see Figure 12. However, the $D_{0}$ of the complex with the polarizable benzene molecule $\left(\bar{\alpha}=8.89 \AA^{3}\right)$ is slightly smaller than that of the furan complex, see also Table III and Figure 12. Since cyclopropane and benzene are nonpolar, there is no dipole-dipole-interaction with the dipole moment of $1 \mathrm{NpOH}$, in contrast to furan. We propose that the larger $D_{0}$ of the $1 \mathrm{NpOH}$-furan complex is due to this additional electrostatic interaction.

The average polarizability of thiophene $\left(\bar{\alpha}=9.8 \AA^{3}\right)$ is only $10 \%$ larger than that of benzene, but the thiophene complex has a $25 \%$ larger $D_{0}$. Again, the $D_{0}$ increase is larger than expected from the relative polarizabilities of the two admolecule, suggesting that electrostatic and inductive contributions contribute to the larger stability of the thiophene complex. In contrast, the $D_{0}$ increase from furan to thiophene is roughly proportional to $\bar{\alpha}$.

A large $D_{0}$ increase by $\sim 75 \%$ occurs upon going from the unsaturated furan to the saturated tetrahydrofuran. As can be seen in Figure 12, the electronic polarizability of THF $\left(\bar{\alpha}=7.97 \AA^{3}\right)$ is only $8 \%$ larger than that of furan. This pair of complexes clearly exemplifies the difference between nonclassical H-bonding (with mainly dispersion contributions) and classical H-bonding (mainly electrostatic and inductive contributions). Accordingly, the $1 \mathrm{NpOH} \cdot \mathrm{THF}$ complex exhibits a short H-bond to one of the ether oxygen lone-pairs, see Figure 9.

Interestingly, a similar $D_{0}$ increase by $\sim 75 \%$ occurs when adding two methyl groups to furan. Figure 12 shows that the polarizability of $2,5-\mathrm{DMF}\left(\bar{\alpha}=11.09 \AA^{3}\right)$ is $40 \%$ larger than that of furan. Here, we attribute the $D_{0}$ increase of 2,5-DMF complex mainly to the increase of dispersion interactions with the $1 \mathrm{NpOH}$ moiety, a more detailed discussion is given in section IV. D.

\section{Calculated and experimental dissociation energies}

The experimental and calculated dissociation energies are compared in Table III. The DFT-D calculated $D_{0}$ values for $1 \mathrm{NpOH}$-cyclopropane agree nicely with experiment, the B3LYP-D3 value 
being within $0.17 \mathrm{~kJ} / \mathrm{mol}$, the B97-D3 value only slightly larger and $\omega \mathrm{B} 97 \mathrm{X}-\mathrm{D}$ slightly lower. For the $1 \mathrm{NpOH} \cdot$ benzene complex, the calculated B97-D3 and B3LYP-D3 $D_{0}$ values are about $2 \mathrm{~kJ} / \mathrm{mol}$ larger than experiment, while the $\omega \mathrm{B} 97 \mathrm{X}-\mathrm{D}$ value is only $0.3 \mathrm{~kJ} / \mathrm{mol}$ larger. For the $1 \mathrm{NpOH} \cdot$ furan complex, the B3LYP-D3 and B97-D3 $D_{0}$ values lie within the experimental $D_{0}$ brackets, while the $\omega \mathrm{B} 97 \mathrm{X}-\mathrm{D}$ value is about $2 \mathrm{~kJ} / \mathrm{mol}$ too low.

In contrast to these good agreements, the experimental $D_{0}$ of the $1 \mathrm{NpOH}$-thiophene complex is $\sim 2.7 \mathrm{~kJ} / \mathrm{mol}$ larger than the B97-D3 and B3LYP-D3 calculated values and nearly $6 \mathrm{~kJ} / \mathrm{mol}$ larger than the $\omega \mathrm{B} 97 \mathrm{X}-\mathrm{D} D_{0}$. Notably, none of the calculated $D_{0}$ values lies within the brackets of the experimental measurement, see Figure 12. The lack of agreement may stem from different errors of the DFT calculations (insufficiently large basis set, problems with the short-range exchangecorrelation, with D3 in general, missing many-body dispersion).

For the THF complex, all three calculated $D_{0}\left(S_{0}\right)$ values lie within the experimental $D_{0}$ brackets, although these are wider than for the other complexes, and do not constitute such a stringent test for the DFT-D methods as discussed above for the cyclopropane, furan and benzene com-

plexes. Although the experimental $D_{0}$ brackets are even wider for the 2,5-DMF complex, the agreement between calculations and experiment is much poorer than for the THF complex, all three values being below the lower $D_{0}$ bracket.

\section{Correlation of nonclassical H-bonding energies with D3 dispersion interactions}

As noted above for the nonclassically H-bonded complexes cyclopropane, furan, benzene and thiophene, the experimental $D_{0}$ values correlate well with the isotropic electronic polarizability $\bar{\alpha}$ of the admolecule. However, given that the polarizabilities $\alpha(\mathrm{S})$ and $\alpha(1 \mathrm{NpOH})$ are tensors and that the dispersion interaction depends on the relative orientation of the $1 \mathrm{NpOH}$ and $\mathrm{S}$ moieties, the dispersion stabilization is only roughly modeled by $\bar{\alpha}$. An alternative is to calculate the dispersion interaction energy in terms of atom-atom-interactions at the minimum-energy geometry of the complex, using the D3 method. For this we employed the DFT-D3 parameters ${ }^{60}$ and the D3 program code on the Grimme web page ${ }^{67}$ (note that the latter may or may not be identical to the implementation of the D3 calculation in Gaussian 16).

In Figure 13 we plot the experimental dissociation energies $D_{0}\left(S_{0}\right)$ vs. the calculated D3energies at the respective minimum-energy geometries. The $D_{0} \mathrm{~s}$ of the nonclassically H-bonded cyclopropane, furan, benzene and thiophene complexes correlate nicely with the calculated D3 
part of the binding energy. That the experimental $D_{0}$ for the THF complex lies $\sim 1100 \mathrm{~cm}^{-1}$ above the dashed $D_{0}=D 3$ line suggests that there the non-dispersion (electrostatic, inductive, charge-transfer) stabilizing contributions to the interaction energy are important. As expected from its larger polarizability, the 2,5-DMF complex also exhibits a larger D3-contribution to its binding energy than cyclopropane, furan, benzene and thiophene. However, the experimental $D_{0}$

lies $\sim 600 \mathrm{~cm}^{-1}$ above the dashed line, implying that the non-dispersion (electrostatic, inductive etc.) stabilizing contributions also increase in this complex, relative to the furan complex.

Without the D3 dispersion corrections, the cyclopropane and benzene complexes are predicted not to be bound at their equilibrium geometries (calculated with the D3 correction), and the furan and thiophene complexes are calculated to be only weakly bound. In contrast, the THF and 2,5DMF complexes are predicted to be bound even without the D3 correction. This again implies that the non-dispersion contributions to the H-bonding are large for the latter two complexes.

\section{CONCLUSIONS}

We have determined the $S_{0}$ and $S_{1}$ state intermolecular dissociation energies $D_{0}$ of the 1naphthol $\cdot \mathrm{S}$ hydrogen-bonded complexes with $\mathrm{S}=$ furan, 2,5-dimethylfuran, thiophene and tetrahydrofuran, using the stimulated-emission pumping resonant two-photon ionization (SEP-R2PI) method. The $D_{0}$ of the furan complex was bracketed within $0.3 \mathrm{~kJ} / \mathrm{mol}$, corresponding to a relative uncertainty of $\pm 1.3 \%$. The dissociation energies increase by $1-2 \mathrm{~kJ} / \mathrm{mol}$ upon $S_{0} \rightarrow S_{1}$ excitation of the 1-naphthol moiety.

In parallel, the structures, binding energies $D_{e}$, vibrational frequencies, changes of vibrational zero-point energy $(\triangle \mathrm{VZPE})$ and dissociation energies $D_{0}$ were calculated using the dispersioncorrected density functional methods B97-D3, B3LYP-D3 and $\omega$ B97X-D. All methods predict that hydrogen-bonded Edge structures in which the 1-naphthol $\mathrm{OH}$ group acts as an H-bond donor are most stable. While all methods also predict Face isomers that are bound by dispersion interactions, their calculated $D_{0}$ values are smaller than those of the Edge isomers. This agrees with the lack of experimental observation of any Face isomers.

The dissociation energies calculated with the three methods differ mutually by $6-15 \%$. Relative to experiment, the B3LYP-D3 method reproduced the experimental $D_{0}$ values best, with a minimum deviation of $-0.01 \mathrm{~kJ} / \mathrm{mol}$ ((for the furan complex), a mean absolute deviation (MAD) of $1.7 \mathrm{~kJ} / \mathrm{mol}$ and a maximum difference of $4.1 \mathrm{~kJ} / \mathrm{mol}$ (for the 2,5-dimethylfuran complex). 
The B97-D3 method exhibits a larger MAD of $2.2 \mathrm{~kJ} / \mathrm{mol}$ and a larger maximum difference of $6.8 \mathrm{~kJ} / \mathrm{mol}$, again for 1-naphthol-2,5-dimethylfuran. The $\omega \mathrm{B} 97 \mathrm{X}-\mathrm{D}$ method generally predicts the smallest dissociation energies of the three methods and exhibits the largest differences relative to experiment, with a MAD of $2.6 \mathrm{~kJ} / \mathrm{mol}$ and a maximum difference of $6.67 \mathrm{~kJ} / \mathrm{mol}$ for 1-naphthol-2,5-dimethylfuran. Overall the predictive performances of the three DFT-D methods are encouraging, but the computational MADs are significantly larger than the mean absolute experimental bracketing width, which is $\pm 0.8 \mathrm{~kJ} / \mathrm{mol}$, averaged over the same six complexes.

We compared the $D_{0}\left(S_{0}\right)$ values measured here with those of the nonclassically H-bonded complexes $1 \mathrm{NpOH} \cdot$ cyclopropane and $1 \mathrm{NpOH} \cdot$ benzene and of the classically H-bonded complexes of $1 \mathrm{NpOH}$ with $\mathrm{H}_{2} \mathrm{O}$, alcohols and cyclic ethers. ${ }^{23,27,49,53}$ Plotting $D_{0}\left(S_{0}\right)$ vs. the average molecular polarizability $\bar{\alpha}(\mathrm{S})$ reveals very different dependencies for nonclassically and classically H-bonded complexes: The $D_{0}$ values of the non-classically $\mathrm{H}$-bonded complexes increase roughly linearly with increasing $\bar{\alpha}(\mathrm{S})$ of the solvent, suggesting that the dispersion part of the interaction energy is the dominating contribution to non-classical H-bonds. This is supported by the calculated D3 contributions to the intermolecular binding energy, which also show a near-linear correlation of $D_{0}$ with the D3 energy. In contrast, the classically H-bonded complexes exhibit a steep initial rise of $D_{0}$ with $\bar{\alpha}(\mathrm{S})$, reaching larger $D_{0}$ values than for the nonclassically H-bonded complexes, which is then followed by a slower increase with $\bar{\alpha}(\mathrm{S})$. This implies that the dispersion part of the interaction energy contributes less to the total energy in classically H-bonded complexes. Since both $D_{0}$ and $\bar{\alpha}(\mathrm{S})$ are experimental quantities, this $D_{0}$ vs. $\bar{\alpha}(\mathrm{S})$ pattern allows to experimentally differentiate nonclassically and classically H-bonded complexes.

We suggest that intermolecular energy partitioning methods such as SAPT (symmetry-adapted perturbation theory ${ }^{68}$ or DFT-SAPT ${ }^{69-71}$ be applied to these Edge complexes in order to deepen the understanding of the different energy contributions to their binding energies, and possibly assist in the development of improved theoretical methods.

\section{Supplementary Material}

See supplementary material for a SEP-R2PI scheme (Fig. S1), UV/UV hole-burning and probe laser spectra (Figs. S2-S5), views of calculated structures (Figs. S6 and S7) and Cartesian co-

ordinates of the 1-naphthol.S complexes optimized by the three DFT-D methods (Tables S1 to S36). 


\section{Acknowledgements}

We thank the Swiss National Science Foundation for financial support (grant 200021E-160404). A. Poblotzki (Universität Göttingen) was additionally funded by a travel grant of the Priority Program SPP1807 "Control of London dispersion interactions in molecular chemistry" of the Deutsche Forschungsgemeinschaft (project number 271107160).

* Department of Atomic and Molecular Physics, Manipal University, Manipal-576104, Karnataka, India

$\dagger$ Institut für Physikalische Chemie, Universität Göttingen, Tammannstrasse 6, 37077 Göttingen, Germany

$\ddagger$ leutwyler@dcb.unibe.ch

1 G. A. Jeffrey, An Introduction to Hydrogen Bonding (Oxford University Press, Oxford, 1997).

2 J. E. Del Bene and M. J. T. Jordan, Int. Rev. Phys. Chem. 18, 119 (1999).

3 G. A. Jeffrey and W. Saenger, Hydrogen Bonding in Biological Structures (Springer, Berlin, 1991).

4 G. R. Desiraju and T. Steiner, The Weak Hydrogen Bond in Structural Chemistry and Biology (Oxford University Press, 2001).

5 T. Steiner, Angew. Chem. Int. Ed. 41, 48 (2002).

6 G. R. Desiraju, Acc. Chem. Res. 35, 565 (2002).

7 S. Grimme, J. Comput. Chem. 25, 1463 (2004).

8 S. Grimme, J. Comput. Chem. 27, 1787 (2006).

9 J.-D. Chai and M. Head-Gordon, Phys. Chem. Chem. Phys. 10, 6615 (2008).

10 L. Goerigk and S. Grimme, J. Chem. Theory Comput. 7, 291 (2011).

11 L. Goerigk and S. Grimme, Phys. Chem. Chem. Phys. 13, 6670 (2011).

12 W. Hujo and S. Grimme, Phys.Chem.Chem.Phys. 13, 13942 (2011).

13 P. Jurečka, J. Šponer, J. Černy, and P. Hobza, Phys. Chem. Chem. Phys. 8, 1985 (2006).

14 J. Řezáč, K. E. Riley, and P. Hobza, J. Chem. Theory Comput. 7, 2427 (2011), http://dx.doi.org/10.1021/ct2002946.

15 J. Řezáč, K. E. Riley, and P. Hobza, J. Chem. Theory Comput. 7, 3466 (2011).

16 J. Řezáč and P. Hobza, J. Chem. Theory Comput. 8, 141 (2012).

17 R. Podeszwa, K. Patkowski, and K. Szalewicz, Phys. Chem. Chem. Phys. 12, 5974 (2010). 
18 T. Takatani, E. G. Hohenstein, M. Malagoli, M. S. Marshall, and C. D. Sherrill, J. Chem. Phys. 132, 144104 (2010).

19 D. E. Taylor, J. G. Angyan, G. Galli, C. Zhang, F. Gygi, K. Hirao, J. W. Song, K. Rahul, O. A. von Lilienfeld, R. Podeszwa, I. W. Bulik, T. M. Henderson, G. E. Scuseria, J. Toulouse, R. Peverati, D. G. Truhlar, and K. Szalewicz, J. Chem. Phys. 145, 124105 (2016).

20 J. F. Ogilvie and F. Y. H. Wang, J. Mol. Struct. 273, 277 (1992).

21 J. F. Ogilvie and F. Y. H. Wang, J. Mol. Struct. 291, 313 (1993).

22 R. A. Mata and M. A. Suhm, Angew. Chemie Int. Ed. 56, 11011 (2017).

23 C. Wickleder, T. Droz, T. Bürgi, and S. Leutwyler, Chem. Phys. Lett. 264, 257 (1997).

24 J. E. Braun, T. L. Grebner, and H. J. Neusser, J. Phys. Chem. A 102, 3273 (1998).

25 J. E. Braun, T. Mehnert, and H. J. Neusser, Int. J. Mass. Spec. 203, 1 (2000).

26 M. Mons, I. Dimicoli, and F. Piuzzi, Int. Rev. Phys. Chem. 21, 101 (2002), http://dx.doi.org/10.1080/01442350110104310.

27 C. Wickleder, D. Henseler, and S. Leutwyler, J. Chem. Phys. 116, 1850 (2002).

28 J. A. Frey, C. Holzer, W. Klopper, and S. Leutwyler, Chem. Rev. 116, 5614 (2016).

29 S. Georgiev and H. Neusser, J. Electron. Spectrosc. Relat. Phenomena 142, 207 (2005).

30 J. L. Knee, L. R. Khundkar, and A. H. Zewail, J. Chem. Phys. 87, 115 (1987).

31 H. Abe, N. Mlkaml, and M. Ito, J. Phys. Chem. 86, 1768 (1982).

32 A. J. Gotch and T. S. Zwier, J. Chem. Phys. 96, 3388 (1992).

33 A. Courty, M. Mons, I. Dimicoli, F. Piuzzi, M.-P. Gaigeot, V. Brenner, P. de Pujo, and P. Millié, J. Phys. Chem. A 102, 6590 (1998).

34 B. E. Rocher-Casterline, L. C. Ch’'ng, A. K. Mollner, and H. Reisler, J. Chem. Phys 134, 211101 (2011).

35 L. C. Ch’ng, A. K. Samanta, G. Czakó, J. M. Bowman, and H. Reisler, J. Am. Chem. Soc. 134, 15430 (2012), http://dx.doi.org/10.1021/ja305500x.

36 A. K. Samanta, L. C. Ch'ng, and H. Reisler, Chem. Phys. Lett. 575, 1 (2013).

37 L. C. Ch'ng, A. K. Samanta, Y. Wang, J. M. Bowman, and H. Reisler, J. Phys. Chem. A 117, 7207 (2013), pMID: 23536966, http://dx.doi.org/10.1021/jp401155v.

38 A. K. Samanta, Y. Wang, J. S. Mancini, J. M. Bowman, and H. Reisler, Chem. Rev. 116, 4913 (2016).

39 K. E. Riley, M. Pitoňák, P. Jurečka, and P. Hobza, Chem. Rev. 110, 5023 (2010), http://dx.doi.org/10.1021/cr1000173.

40 S. Grimme, A. Hansen, J. G. Brandenburg, and C. Bannwarth, Chem. Rev. 116, 5105 (2016). 
41 C. Holzer and W. Klopper, Mol. Phys. 115, 2775 (2017).

42 C. Holzer and W. Klopper, J. Chem. Phys. 147, 181101 (2017).

43 T. Bürgi, T. Droz, and S. Leutwyler, Chem. Phys. Lett. 225, 351 (1994).

44 T. Droz, T. Bürgi, and S. Leutwyler, J. Chem. Phys. 103, 4035 (1995).

45 T. Droz, T. Bürgi, and S. Leutwyler, Ber. Bunsenges. Phys. Chem. 99, 429 (1995).

46 S. Leutwyler and J. Jortner, J. Phys. Chem. 91, 5558 (1987).

47 N. Ben-Horin, U. Even, J. Jortner, and S. Leutwyler, J. Chem. Phys. 97, 5296 (1992).

48 T. Bürgi, T. Droz, and S. Leutwyler, J. Chem. Phys. 103, 7228 (1995).

49 S. Maity, R. Knochenmuss, C. Holzer, G. Féraud, J. A. Frey, W. Klopper, and S. Leutwyler, J. Chem. Phys. 145, 164304 (2016).

50 S. Maity, P. Ottiger, F. A. . Balmer, R. Knochenmuss, and S. Leutwyler, J. Chem. Phys. 145, 244314 (2016).

51 R. Knochenmuss, S. Maity, and S. Leutwyler, Chimia 71, 7 (2017).

52 R. Knochenmuss, R. K. Sinha, and S. Leutwyler, J. Chem. Phys. 148, 134302 (2018).

53 T. Bürgi, T. Droz, and S. Leutwyler, Chem. Phys. Lett. 246, 291 (1995).

54 R. Knochenmuss, S. Maity, F. Balmer, C. Müller, and S. Leutwyler, J. Chem. Phys. 149, 034306 (2018).

55 P. M. Felker and A. H. Zewail, in Femtosecond Chemistry, Vol. I, edited by J. Manz and L. Wöste (VCH, Weinheim, 1995) Chap. 5.

56 A. Poblotzki, J. Altnöder, and M. A. Suhm, Phys. Chem. Chem. Phys. 18, 27265 (2016).

57 A. Poblotzki, H. C. Gottschalk, and M. Suhm, J. Phys. Chem. Lett 8, 5656 (2017).

58 H. C. Gottschalk, A. Poblotzki, M. A. Suhm, M. M. Al-Mogren, J. Antony, A. A. Auer, L. Baptista, D. M. Benoit, G. Bistoni, F. Bohle, R. Dahmani, D.Firaha, S. Grimme, A. Hansen, M. E. Harding, M. Hochlaf, C. Holzer, G. Jansen, W.Klopper, W. A. Kopp, L. C. Kröger, K. Leonhard, H. Mouhib, F. Neese, M. N. Pereira, I. S. Ulusoy, A. Wuttke, and R. A. Mata, J. Chem. Phys. 148, 014301 (2018).

59 L. Goerigk and S. Grimme, J. Chem. Phys. 132, 184103 (2010).

60 S. Grimme, J. Antony, S. Ehrlich, and H. Krieg, J. Chem. Phys. 132, 154104 (2010).

61 M. J. Frisch, G. W. Trucks, H. B. Schlegel, G. E. Scuseria, M. A. Robb, J. R. Cheeseman, G. Scalmani, V. Barone, G. A. Petersson, H. Nakatsuji, X. Li, M. Caricato, A. V. Marenich, J. Bloino, B. G. Janesko, R. Gomperts, B. Mennucci, H. P. Hratchian, J. V. Ortiz, A. F. Izmaylov, J. L. Sonnenberg, D. WilliamsYoung, F. Ding, F. Lipparini, F. Egidi, J. Goings, B. Peng, A. Petrone, T. Henderson, D. Ranasinghe, V. G. Zakrzewski, J. Gao, N. Rega, G. Zheng, W. Liang, M. Hada, M. Ehara, K. Toyota, R. Fukuda, 
J. Hasegawa, M. Ishida, T. Nakajima, Y. Honda, O. Kitao, H. Nakai, T. Vreven, K. Throssell, J. A. Montgomery, Jr., J. E. Peralta, F. Ogliaro, M. J. Bearpark, J. J. Heyd, E. N. Brothers, K. N. Kudin, V. N. Staroverov, T. A. Keith, R. Kobayashi, J. Normand, K. Raghavachari, A. P. Rendell, J. C. Burant, S. S. Iyengar, J. Tomasi, M. Cossi, J. M. Millam, M. Klene, C. Adamo, R. Cammi, J. W. Ochterski, R. L. Martin, K. Morokuma, O. Farkas, J. B. Foresman, and D. J. Fox, “Gaussian 16 Revision A.03,” (2016), gaussian Inc. Wallingford CT.

62 F. A. Balmer, P. Ottiger, C. Pfaffen, and S. Leutwyler, J. Phys. Chem. A 117, 10702 (2013).

63 F. A. Balmer, P. Ottiger, and S. Leutwyler, J. Phys. Chem. A 119, 10462 (2015).

64 A. Amirav and J. Jortner, Chemical Physics 85, 19 (1984).

65 J. Bösiger and S. Leutwyler, Chem. Rev. 90, 489 (1990).

66 V. A. Rayón and J. L. Sordo, J. Chem. Phys. 122, 204303 (2005).

67 https://www.chemie.uni-bonn.de/pctc/mulliken-center/software/dft-d3/ (2016).

68 B. Jeziorski, K. Szalewicz, and G. Chalasinski, Int. J. Quant. Chem. 14, 271 (1978).

69 A. Hesselmann, G. Jansen, and M. Schütz, J. Chem. Phys. 122, 014103 (2005).

70 T. M. Parker, L. A. Burns, R. M. Parrish, A. G. Ryno, and C. D. Sherrill, J. Chem. Phys. 140, 094106 (2014).

71 G. Jansen, WIREs Comput. Mol. Sci. 4, 127 (2014). 
TABLE I. Experimental and B97-D3 calculated intermolecular fundamental frequencies and changes of vibrational zero-point energies $\Delta$ VZPE (in $\mathrm{cm}^{-1}$ ) of the 1-naphthol.S hydrogen-bonded complexes with $\mathrm{S}=$ furan, thiophene, 2,5-dimethylfuran and tetrahydrofuran.

\begin{tabular}{lcccccccccccccccc}
\hline \hline Admolecule S & \multicolumn{4}{c}{ Experimental freqs. } & \multicolumn{4}{c}{ B97-D3 harmonic freqs. } & \multicolumn{4}{c}{$\Delta$ VZPE (B97-D3 calc.) } \\
& $\tilde{\nu}_{X}$ & $\tilde{\nu}_{Y}$ & $\tilde{\nu}_{Z}$ & $\tilde{\nu}_{r o t, 1}$ & $\tilde{\nu}_{r o t, 2}$ & $\tilde{\nu}_{r o t, 3}$ & $\tilde{\nu}_{X}$ & $\tilde{\nu}_{Y}$ & $\tilde{\nu}_{Z}$ & $\tilde{\nu}_{r o t, 1}$ & $\tilde{\nu}_{r o t, 2}$ & $\tilde{\nu}_{r o t, 3}$ & inter & $\Delta$ intra & Total \\
\hline Furan $^{a}$ & 9 & 31 & 45 & $\ldots$ & $\ldots$ & $\ldots$ & 3.9 & 30.6 & 38.8 & 57.9 & 71.0 & 81.6 & $142(53 \%)$ & $128(47 \%)$ & 270 \\
Thiophene $^{b}$ & 9 & $\ldots$ & $\ldots$ & 50 & $\ldots$ & $\ldots$ & 14.2 & 21.8 & 37.2 & 59.1 & 68.6 & 90.0 & $145(62 \%)$ & $89(38.0 \%)$ & 235 \\
2,5-Dimethylfuran & $c$ & 8 & 11 & 31 & $\ldots$ & $\ldots$ & 77 & 4.5 & 20.3 & 46.6 & 55.0 & 72.9 & 77.3 & $138(38 \%)$ & $223(62 \%)$ & 361 \\
Tetrahydrofuran $^{d}$ & $\ldots$ & 34 & 43 & $\ldots$ & $\ldots$ & $\ldots$ & 29.1 & 60.6 & 78.0 & 13.8 & 99.8 & 117.9 & $200(39 \%)$ & 309 & $(61 \%)$ & 509 \\
\hline
\end{tabular}

${ }^{\text {a }}$ Calculated values are for isomer 1.

${ }^{\mathrm{b}}$ Calculated values are for isomer 2.

${ }^{\mathrm{c}}$ Calculated values are for isomer 1.

${ }^{\mathrm{d}}$ Calculated values are for isomer 1. 
TABLE II. Experimental dissociation energies $D_{0}\left(S_{0}\right)$ and $D_{0}\left(S_{1}\right)$ and spectral shifts $\delta \tilde{\nu}$ of hydrogen bonded 1-naphthol-S complexes. The true $D_{0}$ may lie anywhere within the bracketed interval with equal probability.

\begin{tabular}{|c|c|c|c|c|c|}
\hline \multirow[t]{2}{*}{ Adduct } & \multicolumn{2}{|c|}{$D_{0}\left(S_{0}\right)$} & \multicolumn{2}{|c|}{$D_{0}\left(S_{1}\right)$} & \multirow{2}{*}{$\begin{array}{c}\delta \tilde{\nu} \\
\mathrm{cm}^{-1}\end{array}$} \\
\hline & $\mathrm{cm}^{-1}$ & $\mathrm{~kJ} / \mathrm{mol}$ & $\mathrm{cm}^{-1}$ & $\mathrm{~kJ} / \mathrm{mol}$ & \\
\hline Thiophene & $2221 \pm 48$ & $26.56 \pm 0.57$ & $2290 \pm 48$ & $27.38 \pm 0.47$ & $-69 \pm 1$ \\
\hline Furan & $1824 \pm 24$ & $21.82 \pm 0.29$ & $1905 \pm 25$ & $22.79 \pm 0.29$ & $-81 \pm 1$ \\
\hline 2,5-Dimethylfuran & $3052 \pm 191$ & $36.5 \pm 2.3$ & $3145 \pm 191$ & $37.6 \pm 2.3$ & $-93 \pm 1$ \\
\hline Tetrahydrofuran & $3146 \pm 108$ & $37.63 \pm 1.29$ & $3328 \pm 108$ & $39.66 \pm 1.29$ & $-182 \pm 1$ \\
\hline Cyclopropane edge $^{a}$ & $1283 \pm 3$ & $15.34 \pm 0.03$ & $1354 \pm 3$ & $16.20 \pm 0.04$ & $-72 \pm 1$ \\
\hline Benzene $^{b}$ & $1773 \pm 25$ & $21.21 \pm 0.30$ & $1839.5 \pm 25$ & $22.00 \pm 0.30$ & $-66 \pm 1$ \\
\hline Benzene- $d_{6}{ }^{b}$ & $1778 \pm 21$ & $21.26 \pm 0.25$ & $1884 \pm 21$ & $22.53 \pm 0.25$ & $-66 \pm 1$ \\
\hline
\end{tabular}

${ }^{a}$ from ref. 49.

${ }^{b}$ from ref. 23. 
TABLE III. Experimental and calculated $S_{0}$ state dissociation energies $D_{0}\left(S_{0}\right)$ (in kJ/mol) of the H-bonded 1-naphthol complexes with cyclopropane, benzene, furan, thiophene, 2,5-dimethylfuran and tetrahydrofuran. The calculated vibrational zero-point energy changes $\triangle$ VZPE are given in parentheses. Calculations employed the dispersion-corrected DFT methods B97-D3, B3LYP-D3 and $\omega$ B97X-D. For each complex the calculated $D_{0}$ in best agreement with experiment is marked in bold.

\begin{tabular}{lcccc}
\hline \hline Complex & Experimental & B97-D3 & B3LYP-D3 & $\omega$ B97X-D \\
& & $D_{0}(\Delta$ VZPE $)$ & $D_{0}(\Delta$ VZPE $)$ & $D_{0}(\Delta$ VZPE $)$ \\
\hline Furan & $21.82 \pm 0.29$ & $21.58(2.74)^{c}$ & $\mathbf{2 1 . 8 1}(2.97)^{a}$ & $19.89(3.18)^{a}$ \\
Thiophene & $26.56 \pm 0.57$ & $\mathbf{2 4 . 1 5}(2.81)^{c}$ & $23.76(2.80)^{a}$ & $20.77(3.19)^{a}$ \\
2,5-Dimethylfuran & $36.5 \pm 2.3$ & $29.69(4.32)^{d}$ & $\mathbf{3 2 . 4 1}(4.33)^{b}$ & $29.83(5.03)^{b}$ \\
Tetrahydrofuran & $37.63 \pm 1.29$ & $36.61(5.55)^{c}$ & $38.94(5.86)^{a}$ & $\mathbf{3 7 . 3 4}(6.00)^{b}$ \\
\hline Cyclopropane edge $^{a}$ & $15.34 \pm 0.03$ & $15.79(3.63)$ & $\mathbf{1 5 . 5 1}(3.68)$ & $14.61(4.27)$ \\
Benzene $^{b}$ & $21.21 \pm 0.30$ & $23.28(2.64)$ & $23.13(2.59)$ & $\mathbf{2 1 . 5 3}(2.94)$ \\
\hline Mean absolute deviation (MAD) $^{2}$ & 2.2 & 1.7 & 2.6 \\
\hline \hline
\end{tabular}

${ }^{a}$ from ref. 49.

${ }^{b}$ from ref. 23 .

${ }^{\mathrm{c}}$ Calculated values for the most stable isomer 2

${ }^{\mathrm{d}}$ Calculated values for the most stable isomer 1 


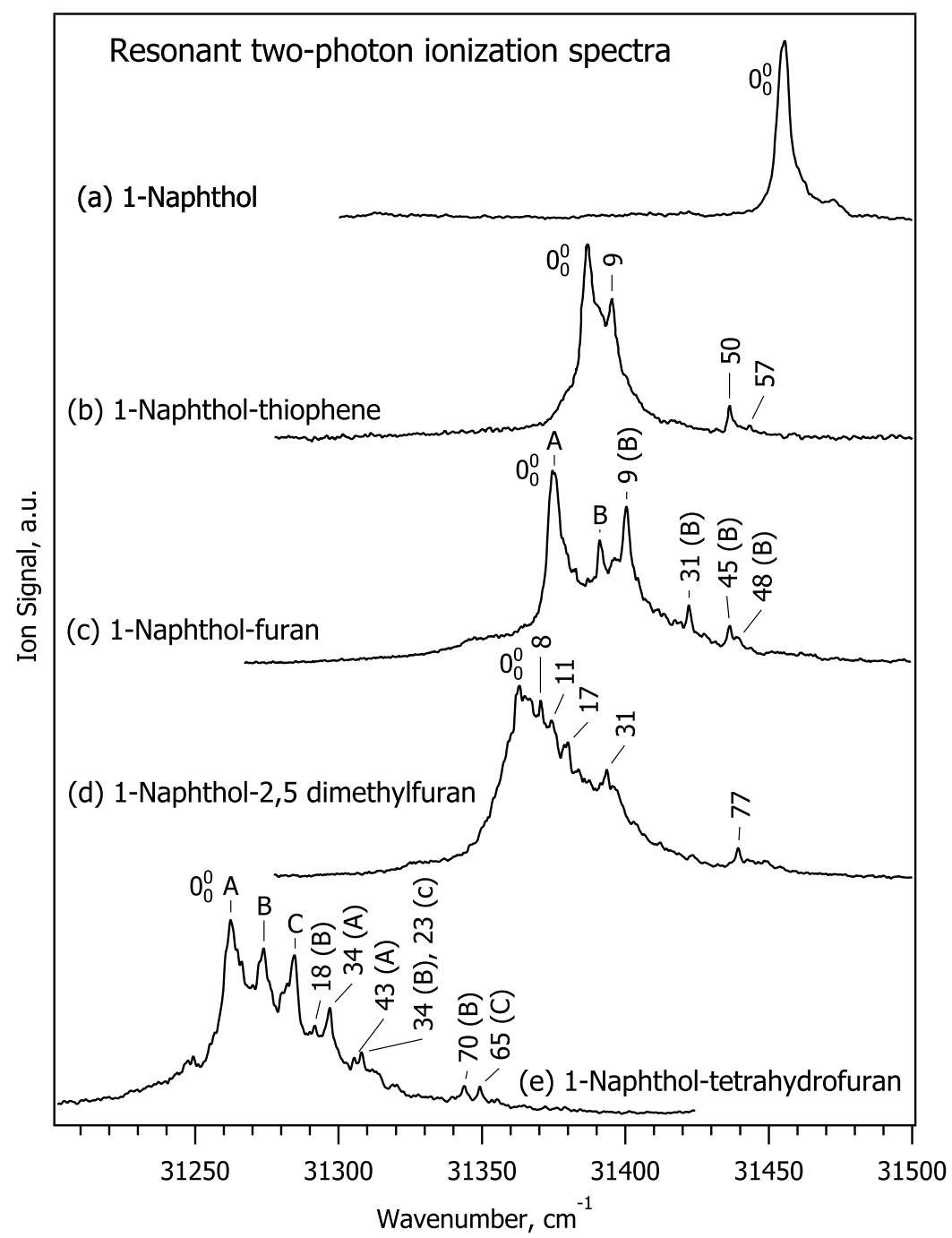

FIG. 1. One-color resonant-two-photon ionization spectra of (a) 1-naphthol and its complexes with (b) thiophene, (c) furan, (d) 2,5-dimethylfuran and (e) tetrahydrofuran. The R2PI and UV-holeburned spectra of the furan and tetrahydrofuran complexes are shown in the supplementary Figures S2 and S3 (SI). The most intense $S_{1}$ state intermolecular vibronic bands are labeled with their wavenumber; for assignments see Table I. 


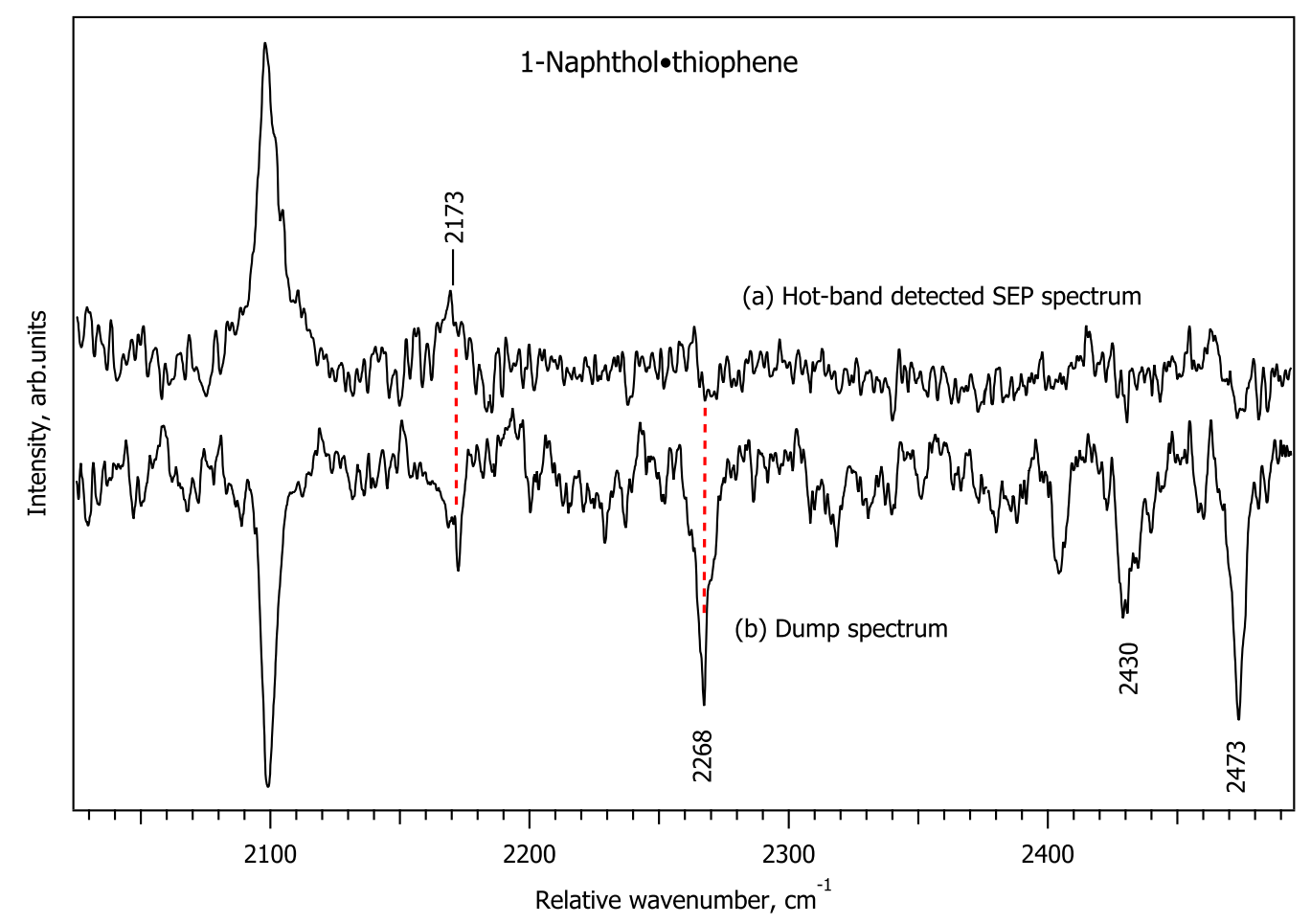

FIG. 2. (a) Hot-band probed SEP-R2PI and (b) dump spectra of the 1-naphthol-thiophene complex. The $\mathrm{x}$-axis is the difference between the pump and dump laser wavenumber. The $D_{0}\left(S_{0}\right)$ is bracketed by the highest-energy vibronic level at $2173 \mathrm{~cm}^{-1}$ observed in spectrum (a) and the next higher band at $2268 \mathrm{~cm}^{-1}$ that appears in the dump spectrum (b), but not in (a), see the vertical red dashed lines. 


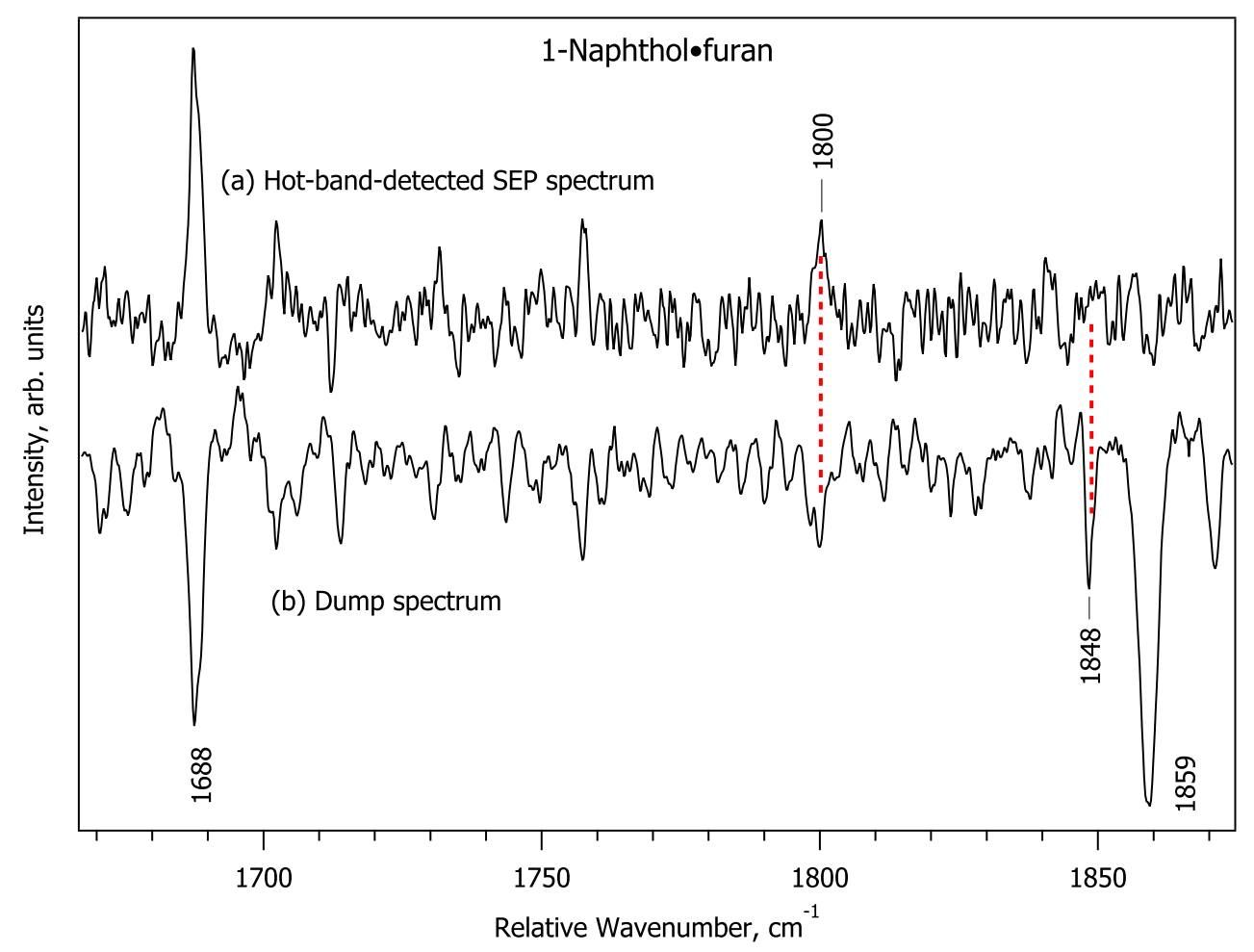

FIG. 3. (a) Hot-band probed SEP-R2PI and (b) dump spectra of the 1-naphthol-furan complex. The x-axis is the difference between the pump and dump laser wavenumber. The $D_{0}\left(S_{0}\right)$ is bracketed by the highestenergy vibronic level at $1800 \mathrm{~cm}^{-1}$ observed in spectrum (a) and the next higher band at $1848 \mathrm{~cm}^{-1}$ that appears in spectrum (b) but not in (a), see the vertical red dashed lines. 


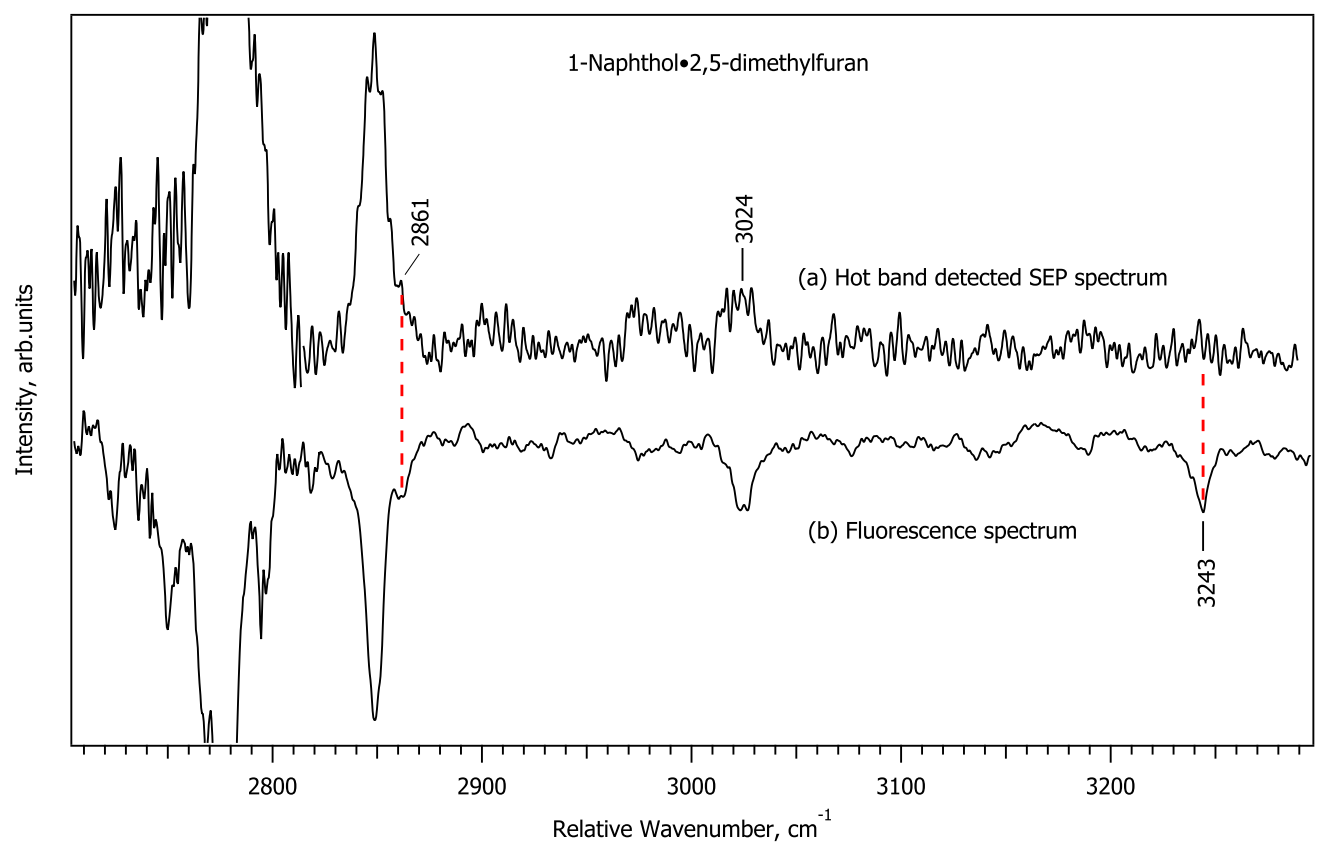

FIG. 4. (a) Hot-band probed SEP-R2PI and (b) fluorescence spectra of the 1-naphthol-2,5-dimethylfuran complex. The fluorescence spectrum was excited at the $0_{0}^{0}$ band $\left(31362 \mathrm{~cm}^{-1}\right)$. For (a), the $\mathrm{x}$-axis is the difference between the pump and dump laser wavenumber, for (b) the difference between the pump and fluorescence wavenumber. The $D_{0}\left(S_{0}\right)$ is bracketed by the highest-energy vibronic level at $2861 \mathrm{~cm}^{-1}$ observed in spectrum (a) and the next higher band at $3243 \mathrm{~cm}^{-1}$ in the fluorescence spectrum, see the vertical red dashed lines. 


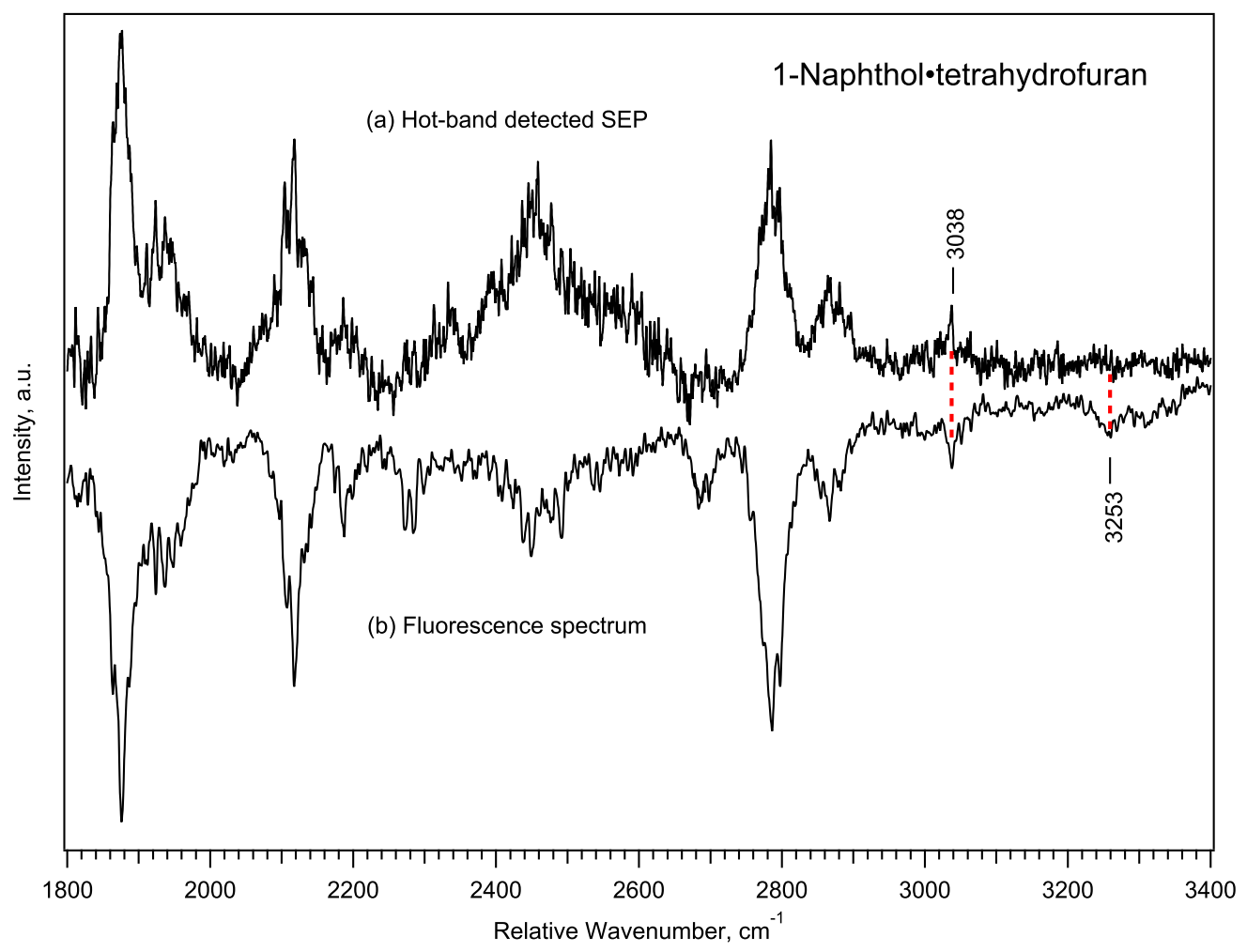

FIG. 5. (a) Hot-band detected SEP-R2PI and (b) fluorescence spectra of the 1-naphthol-tetrahydrofuran complex. The fluorescence spectrum was excited at the $0_{0}^{0}$ band of isomer B $\left(31274 \mathrm{~cm}^{-1}\right)$, see Figure 1(e). The $\mathrm{x}$-axis is defined as in Figure 4. The $D_{0}\left(S_{0}\right)$ is bracketed by the highest-energy vibronic band at $3038 \mathrm{~cm}^{-1}$ in spectrum (a) and the next higher band at $3253 \mathrm{~cm}^{-1}$ in the fluorescence spectrum indicated by the vertical red dashed lines. 

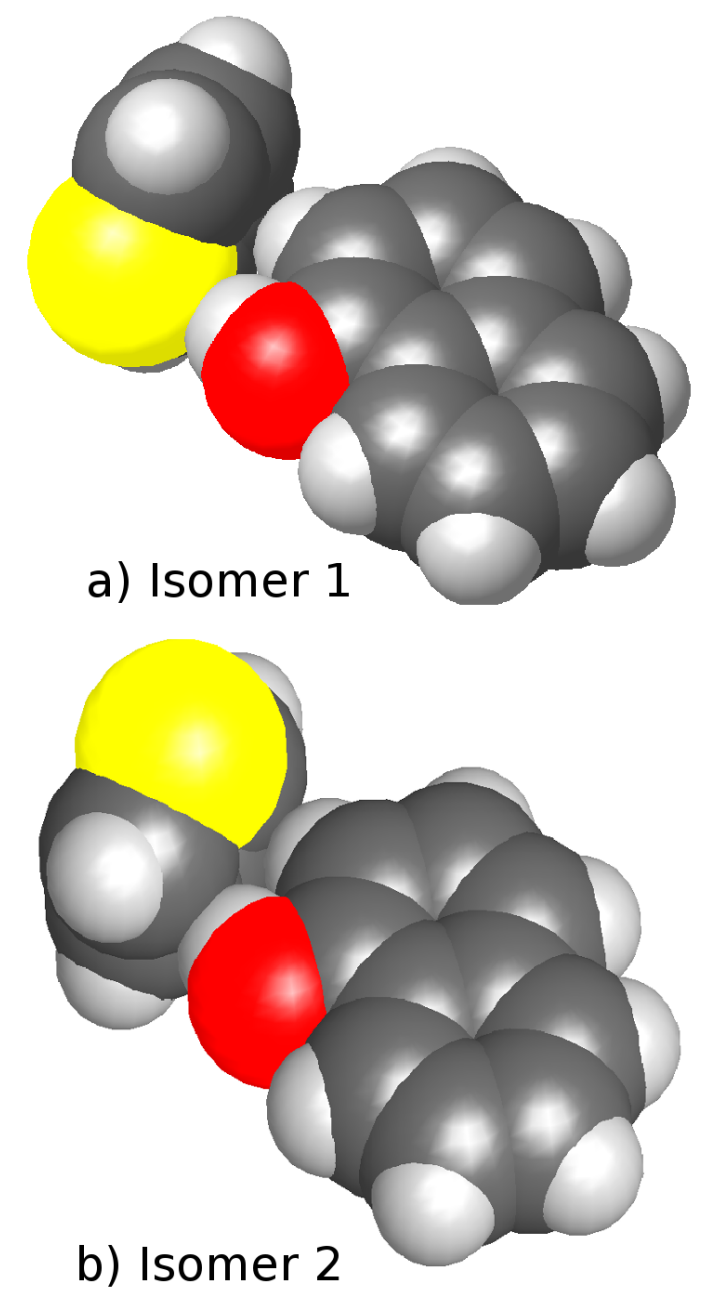

FIG. 6. $\omega$ B97X-D calculated structures of the 1-naphthol-thiophene Edge complexes: (a) Isomer 1, (b) Isomer 2. For additional views of the two isomers, see the supplemental Figure S6, Cartesian coordinates are given in the supplemental Tables S8 and S11. 

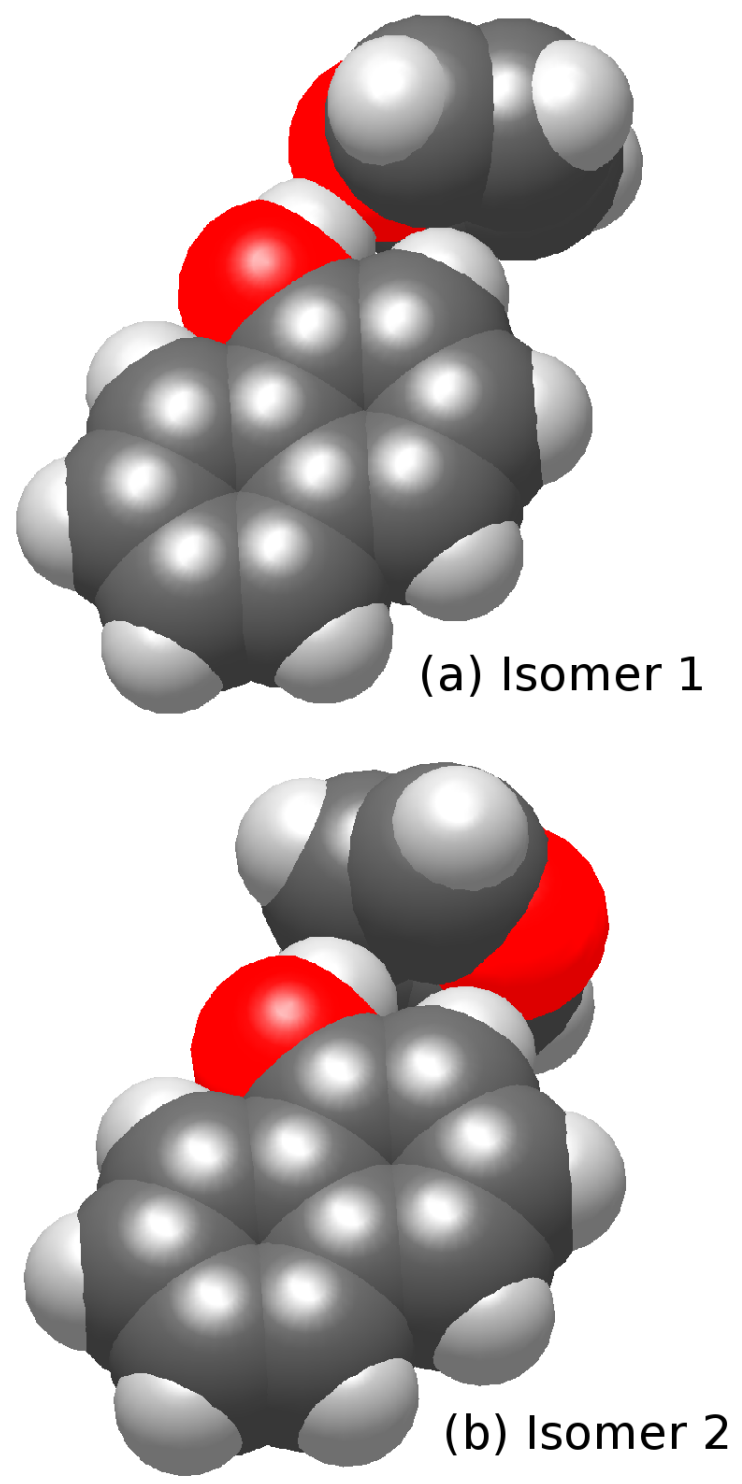

FIG. 7. B97-D3 calculated structures of the 1-naphthol-furan Edge complexes: (a) isomer 1 ( $C_{s}$ symmetric), (b) isomer 2 (no symmetry). For Cartesian coordinates, see the supplemental Tables S17 and S19. 


\section{1-naphthol•2,5-dimethylfuran}

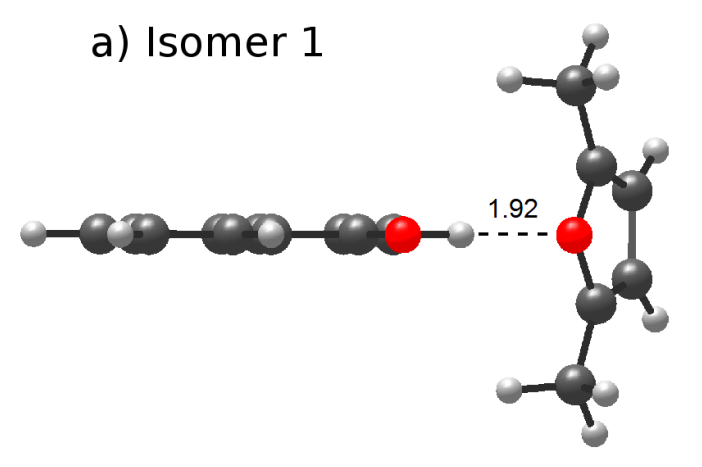

b) Isomer 2

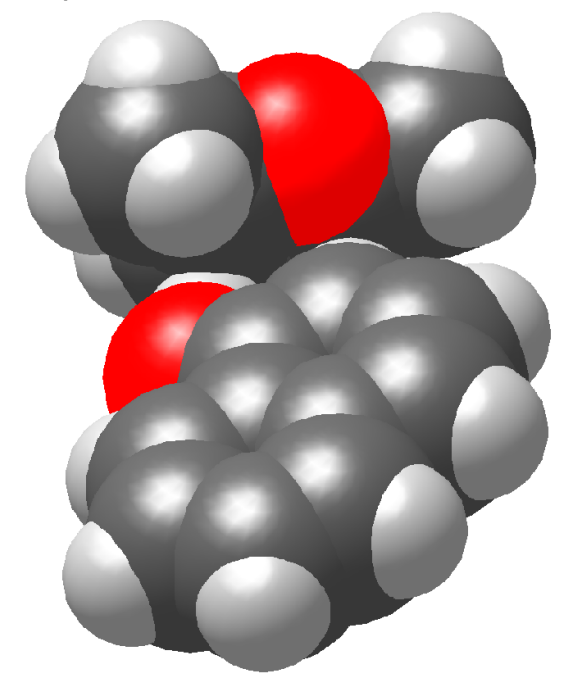

c) Isomer 2

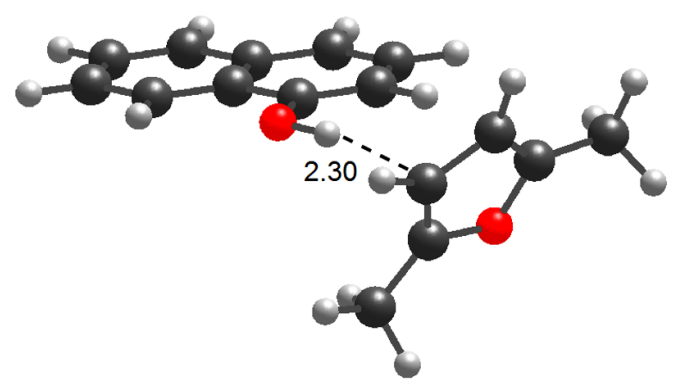

FIG. 8. B97-D3 calculated structures of the 1-naphthol-2,5-dimethylfuran Edge complexes: (a) Isomer 1 ( $C_{s}$ symmetric). (a) Isomer 2 , spacefilling representation, note that the 2,5-dimethylfuran moiety is strongly rotated relative to isomer 1. (c) Isomer 2, in ball-and-stick representation. For Cartesian coordinates of Isomer 1 and 2, see the supplemental Tables S27 and S30. 


\section{1-naphtholotetrahydrofuran}
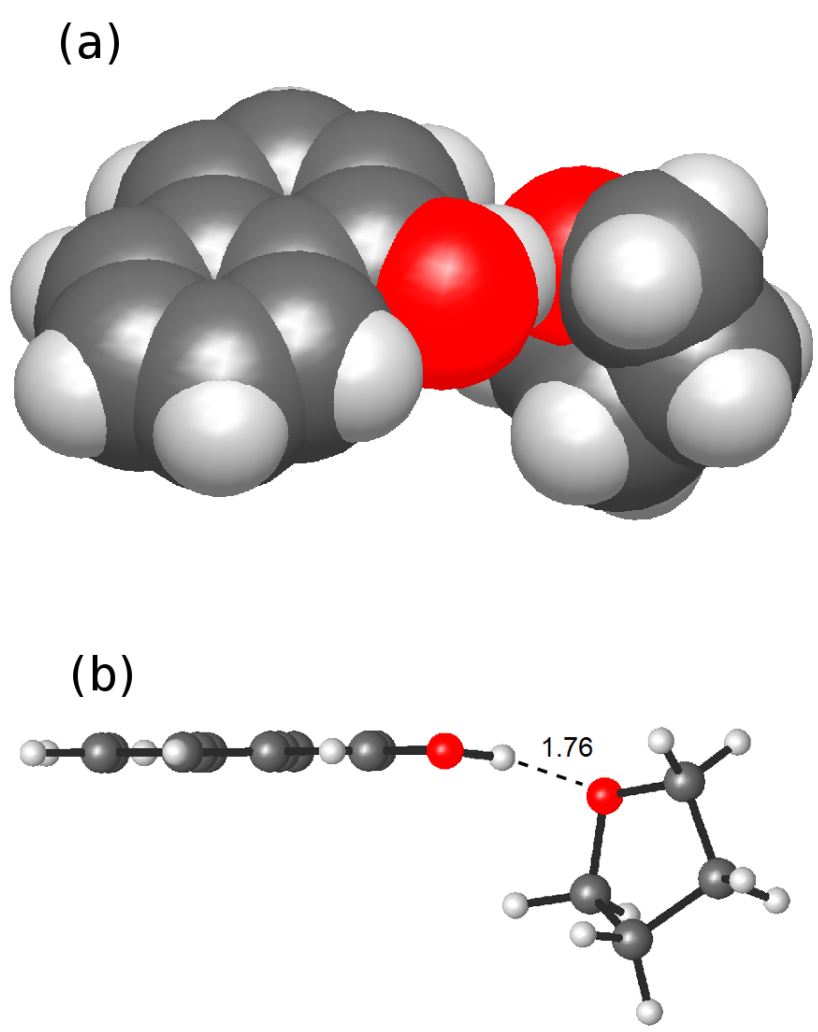

FIG. 9. B97-D3 calculated structure of the most stable 1-naphthol-tetrahydrofuran Edge isomer 3: (a) spacefilling representation, showing the $\mathrm{OH} \cdots \mathrm{O}$ contact. (b) ball-and-stick representation. For Cartesian coordinates see the supplemental Table S32. 


\section{1-naphthol•benzene}

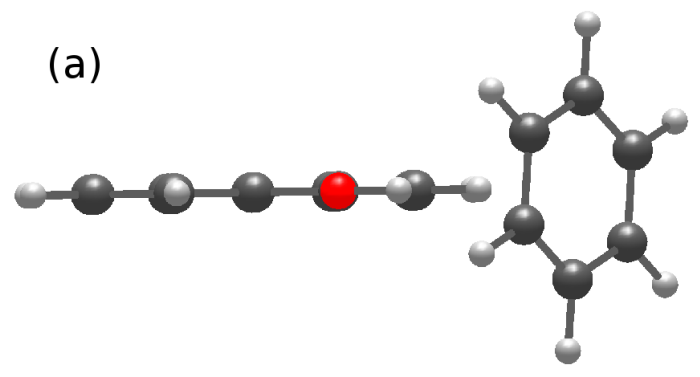

(b)

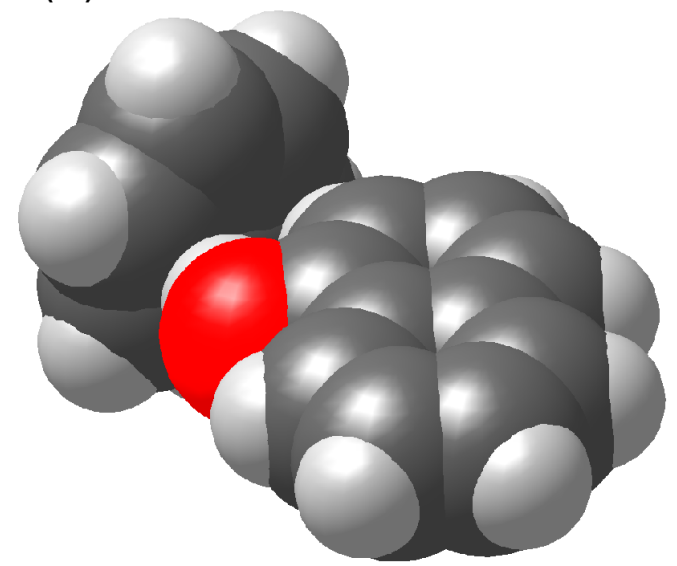

FIG. 10. B97-D3 calculated structure of the 1-naphthol-benzene Edge isomer. (a) Ball-and-stick, (b) spacefilling representation, showing the $\mathrm{OH} \cdots \pi$ and $\mathrm{CH} \cdots \pi$ contacts. For Cartesian coordinates see the supplemental Table S35. 


\section{1-naphthol•cyclopropane}

(a)
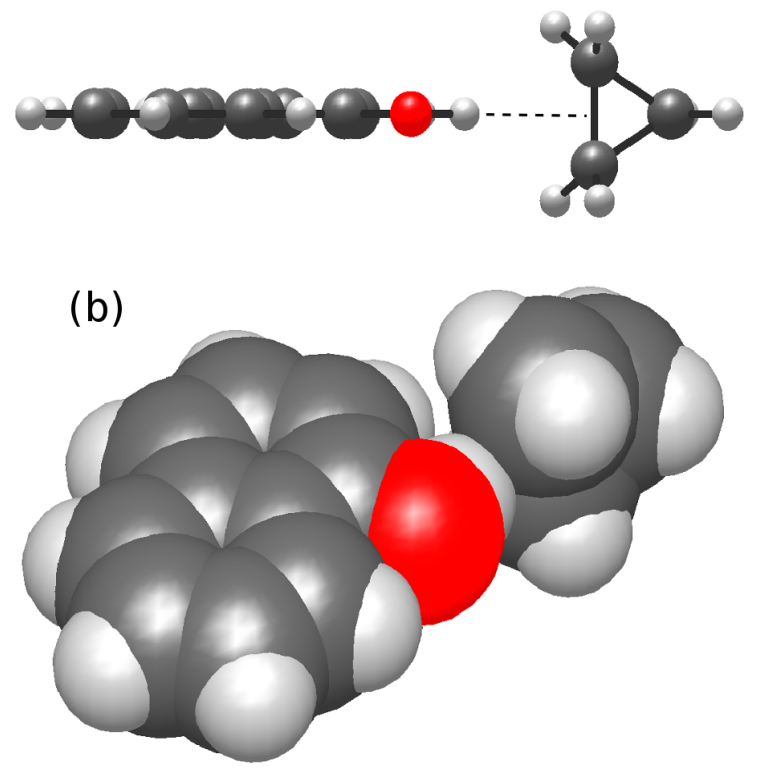

FIG. 11. B97-D3 calculated structure of the 1-naphthol-cyclopropane Edge isomer. (a) Ball-and-stick, (b) spacefilling representation, showing the $\mathrm{OH}$ contact to one of the cyclopropane $\mathrm{C}-\mathrm{C}$ bonds. For Cartesian coordinates see the supplemental Table S36. 


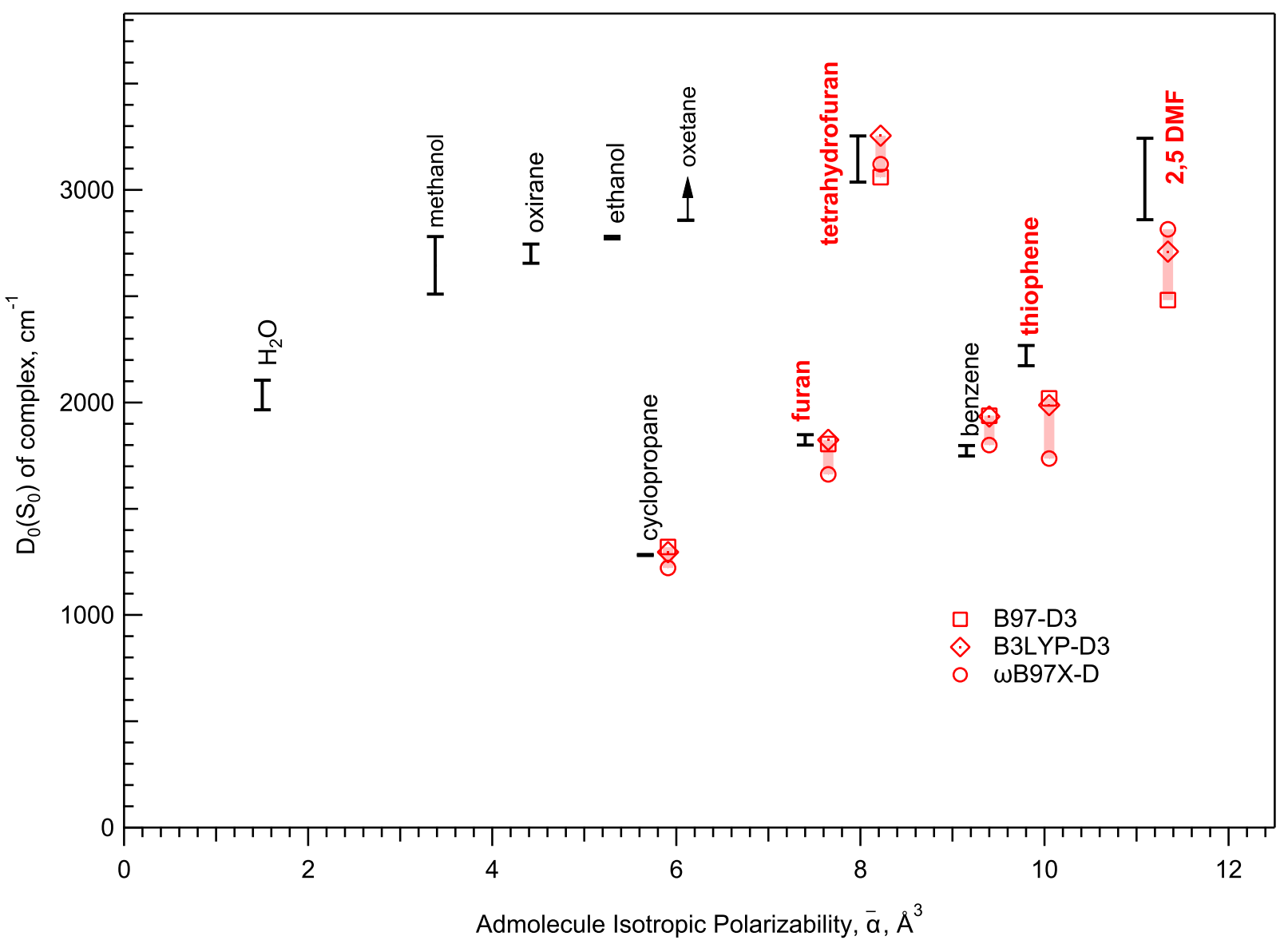

FIG. 12. Experimental ground-state dissociation energies $D_{0}\left(S_{0}\right)$ of the hydrogen bonded 1-naphthol.S complexes measured in this and previous work (refs. 23, 27, 48, and 49) plotted vs. the isotropic electronic polarizability $\bar{\alpha}$ of the admolecule $\mathrm{S}$ (in $\AA^{3}$ ). Values from this work labeled horizontally in red, previous values are labeled vertically in black. The $D_{0}$ values are calculated in this work with the B97-D3, B3LYPD3 and $\omega$ B97X-D methods; they are offset to the right and are indicated in red. 


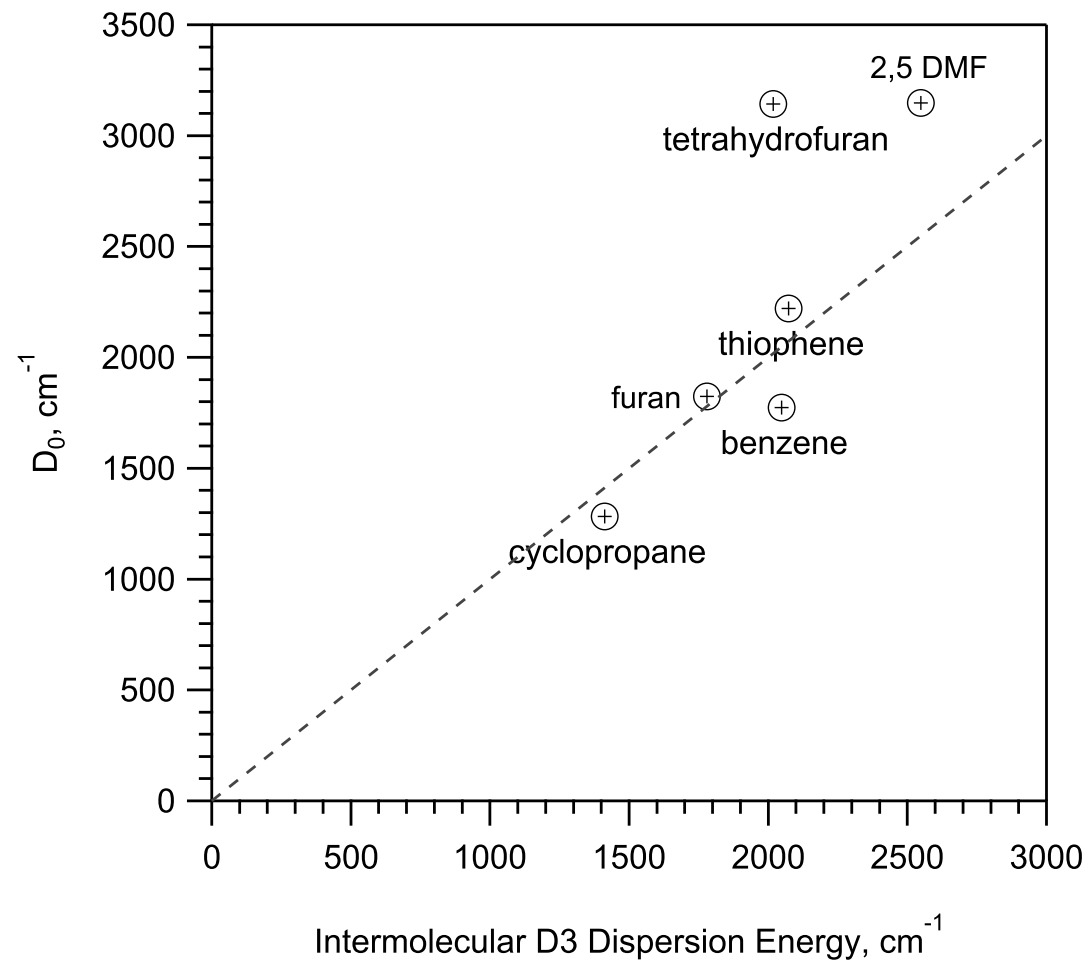

FIG. 13. Experimental dissociation energies $D_{0}\left(S_{0}\right)$ of the six hydrogen-bonded $1 \mathrm{NpOH} \cdot \mathrm{S}$ complexes discussed above, plotted vs. the calculated D3-dispersion contributions to the intermolecular binding energy. ${ }^{60,67}$. The dashed line marks $D_{0}\left(S_{0}\right)=\mathrm{D} 3$, showing the good correlation of $D_{0}\left(S_{0}\right)$ with the D3 contribution for the cyclopropane, furan, benzene and thiophene complexes, see the text. 